\title{
A Regime Switching Model with Exogenous Variables in a Study of Hedge Funds
}

\author{
by \\ Pauline Adamopoulos \\ BComm, Ryerson University, 2010
}

\author{
Research Paper Supervisor: Dr. Pablo Olivares \\ Research Paper Second Reader: Dr. Maurice Roche
}

The Research Paper is submitted

In partial fulfillment of the requirements for the

Master of Arts degree

in

International Economics and Finance

\author{
Ryerson University \\ Toronto, Ontario, Canada
}

(C) Pauline Adamopoulos 2012 


\section{AUTHOR'S DECLARATION}

I hereby declare that I am the sole author of this research paper. This is a true copy of the research paper, including any required final revisions, as accepted by my examiners.

I authorize Ryerson University to lend this research paper to other institutions or individuals for the purpose of scholarly research

I further authorize Ryerson University to reproduce this research paper by photocopying or by other means, in total or in part, at the request of other institutions or individuals for the purpose of scholarly research.

I understand that my research paper may be made electronically available to the public. 


\title{
A Regime Switching Model with Exogenous Variables in a Study of Hedge Funds
}

A Research Paper presented to Ryerson University in partial fulfillment of the requirement for the degree of Master of Arts in International Economics and Finance

By Pauline Adamopoulos

\begin{abstract}
This paper aims to investigate the correlation between states of the global economy, and returns of hedge fund indices while assessing exposure to macroeconomic risk factors.

States of the economy are assumed to follow a three-state Markov chain, and are estimated using the MSCI World Index; estimated states appear to capture most significant global events. State-dependent exposure to macroeconomic and financial factors is assessed with a multivariate regime-switching model which, is then extended to a multivariate quadratic one.

It is concluded that the exposure to any given factor is largely state dependent: different hedge fund indices exhibit exposure to different factors conditional upon the state of the global economy, the ensuing changes in economic indicators, and the changes in capital flows. Furthermore, macroeconomic factors are found to be significant in estimating the returns of hedge fund indices, and quadratic models using both financial and economic factors yield significantly better estimates.
\end{abstract}




\section{Acknowledgments}

I would like to sincerely thank my supervisor, Dr. Pablo Olivares, for his continued support, helpful recommendations and interest in this project. His suggestions lead me to discover topics of mathematics that evoked my curiosity and incited me to further explore these areas of research.

I wish also to acknowledge and genuinely thank my mentor, Dr. Leo Michelis, for his advice and encouragement, as well as Dr. Brennan Thompson for his guidance throughout my masters and for the invaluable discussions.

Additionally, a very sincere thank you is addressed to Simon Pericou for his advice, support, and insightful discussions.

Most of all, I wish to express my deepest appreciation and gratitude to my family, Elena and Kostantinos, for their love, tireless encouragement and unbounded support. Last but not least, I wish to thank my friends who inspired me to continue. 


\section{Contents}

List of Tables $\quad$ v

List of Figures $\quad$ vii

1 Introduction and Literature Review 1

2 Data 3

3 Markov Regime Switching Models $\quad 4$

3.1 States . . . . . . . . . . . . . . . . . . . 4

3.2 Univariate Regime Switching Model . . . . . . . . . . . . . . . . 6

3.3 Multivariate Regime Switching Models . . . . . . . . . . . . . . . 6

3.3.1 Macroeconomic Variables . . . . . . . . . . . . . . 6

3.3.2 Financial Variables . . . . . . . . . . . . . . . . . 8

3.3.3 Financial and Macroeconomic Variables . . . . . . . . . . . . . 9

4 Results and Analysis $\quad 10$

4.1 States . . . . . . . . . . . . . . . . . . . 12

4.2 Univariate Regime Switching Model . . . . . . . . . . . . . . . . . 15

4.3 Multivariate Regime Switching Model . . . . . . . . . . . . . . . . . 16

4.3.1 Macroeconomic Variables . . . . . . . . . . . . . . 18

4.3.2 Financial Variables . . . . . . . . . . . . . . . . . . 21

4.3.3 Financial and Macroeconomic Variables . . . . . . . . . . . . 25

5 Conclusions $\quad 28$ 


\section{List of Tables}

1 Economic Variables . . . . . . . . . . . . . . . . . . 7

2 Financial Variables . . . . . . . . . . . . . . . . . . . . . . . . . . . . 9

3 Descriptive Statistics of Returns . . . . . . . . . . . . . . . . . 10

4 Descriptive Statistics of Net Returns . . . . . . . . . . . . . . . 11

5 Descriptive Statistics of MSCI World Index Returns . . . . . . . . . . . 11

6 Descriptive Statistics of Net MSCI World Index Returns . . . . . . . . 11

7 Estimation of Distribution Parameters . . . . . . . . . . . . . . . 12

8 Parameter Estimates for the Univariate Regime Switching Model in De-

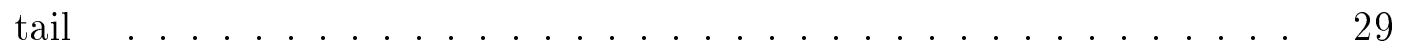

9 Adjusted- $R^{2}$ Values ( $p$-values) for the Univariate Regime Switching Model 29

10 Emerging Markets: Parameter Estimates for the Multivariate Regime Switching Model with Economic Factors in Detail . . . . . . . . . . 30

11 Fund Weighted: Parameter Estimates for the Multivariate Regime Switching Model with Economic Factors in Detail . . . . . . . . . . . . 30

12 Funds of Funds: Parameter Estimates for the Multivariate Regime Switching Model with Economic Factors in Detail . . . . . . . . . . . . . 31

13 Macro: Parameter Estimates for the Multivariate Regime Switching Model with Economic Factors in Detail . . . . . . . . . . . . . . 31

14 Adjusted- $R^{2}$ Values ( $p$-values) for the Multivariate Regime Switching Model with Economic Factors . . . . . . . . . . . . . . . . . . . . 31

15 Emerging Markets: Parameter Estimates for the Quadratic Regime Switching Model with Economic Factors in Detail . . . . . . . . . . . . . 32

16 Fund Weighted: Parameter Estimates for the Quadratic Regime Switching Model with Economic Factors in Detail . . . . . . . . . . . . .

17 Funds of Funds: Parameter Estimates for the Quadratic Regime Switching Model with Economic Factors in Detail . . . . . . . . . . . . 33

18 Macro: Parameter Estimates for the Quadratic Regime Switching Model with Economic Factors in Detail . . . . . . . . . . . . . . .

19 Adjusted- $R^{2}$ Values ( $p$-values) for the Multivariate Quadratic Regime Switching Model with Economic Factors . . . . . . . . . . . . . .

20 Emerging Markets: Parameter Estimates for the Multivariate Regime Switching Model with Financial Factors in Detail . . . . . . . . . . . 35

21 Fund Weighted: Parameter Estimates for the Multivariate Regime Switching Model with Financial Factors in Detail . . . . . . . . . . . 36

22 Funds of Funds: Parameter Estimates for the Multivariate Regime Switching Model with Financial Factors in Detail . . . . . . . . . . . . 37

23 Macro: Parameter Estimates for the Multivariate Regime Switching Model with Financial Factors in Detail . . . . . . . . . . . . 38

24 Adjusted- $R^{2}$ Values ( $p$-values) for the Multivariate Regime Switching Model with Financial Factors . . . . . . . . . . . . . . . . . 38

25 Emerging Markets: Parameter Estimates for the Quadratic Regime Switching Model with Financial Factors in Detail . . . . . . . . . . . . 39 
26 Fund Weighted: Parameter Estimates for the Quadratic Regime Switching Model with Financial Factors in Detail . . . . . . . . . . . 40

27 Funds of Funds: Parameter Estimates for the Quadratic Regime Switching Model with Financial Factors in Detail . . . . . . . . . . . .

28 Macro: Parameter Estimates for the Quadratic Regime Switching Model with Financial Factors in Detail . . . . . . . . . . . . . . . . .

29 Adjusted- $R^{2}$ Values ( $p$-values) for the Multivariate Quadratic Regime Switching Model with Financial Factors . . . . . . . . . . . . . . 42

30 Emerging Markets: Parameter Estimates for the Quadratic Regime Switching Model with both Economic and Financial Factors in Detail . . . . . 43

31 Fund Weighted: Parameter Estimates for the Quadratic Regime Switching Model with both Economic and Financial Factors in Detail . . . . 44

32 Funds of Funds: Parameter Estimates for the Quadratic Regime Switching Model with both Economic and Financial Factors in Detail . . . . .

33 Macro: Parameter Estimates for the Quadratic Regime Switching Model with both Economic and Financial Factors in Detail . . . . . . . . . . .

34 Adjusted- $R^{2}$ Values ( $p$-values) for the Multivariate Quadratic Regime Switching Model with both Economic and Financial Factors . . . . . 46 


\section{List of Figures}

1 Prices of HFRI Indices over time $\ldots \ldots \ldots \ldots \ldots \ldots$

2 States from December 1969 to December 1989 . . . . . . . . . . . . . 14

$3 \quad$ MSCI World Index from December 1969 to December 1989 . . . . . . . 14

4 States from December 1989 to May 2011 . . . . . . . . . . . . . . 15

$5 \quad$ MSCI World Index from December 1989 to May 2011 . . . . . . . . . 15

6 Switching Beta Estimates for Each Index . . . . . . . . . . . . 17 


\section{Introduction and Literature Review}

Various models have been used to model hedge fund performance, among others, OLS rolling regressions and more recently the Kalman filter as well as regime switching models. OLS regression uses a static algorithm which is inappropriate to model hedge fund performance, as hedge fund strategies are dynamic (e.g. Fung and Hsieh, 1997a, 2001). Roncalli and Teïletche (2007) found that the Kalman filter was clearly a more efficient econometric method for hedge fund replication than was OLS. Racicot and Théoret (2009) also came to the conclusion that the dynamic optimization process of the Kalman filter removed some of the arbitrariness inherent in the least squares method of computing the conditional alpha and beta.

It has been shown many times that hedge fund strategies exhibit nonlinear risk-return characteristics, and non-normal payoffs (e.g. Fung and Hsieh, 1997a., 2001, Agarwal and Naik 2004). Alexander and Dimitriu (2005) showed that a long-short strategy hedge fund is more likely to be long equity during up-markets and short equity during down-markets. Goetzmann, Ingersoll, Spiegel and Welch (2006) describe that hedge funds game their strategies according to past returns by using leverage and options, and find that "dynamic manipulation taken in order to influence returns, induces time variation into the return distribution." Goetzmann et al. (2006) also found that the use of regime-switching models of hedge funds is appropriate as many hedge funds implement regime-switching strategies.

The Kalman filter however, is a linear filter and deals poorly with asymmetry and regime changes (French, 2005). As an alternative to the Kalman filter, Hamilton (1989), proposed a filter and smoother to provide nonlinear inference about a discrete-valued unobserved state vector, using Markov switching regression to characterize changes in the parameters of an autoregressive process. This filter was used by Billio, Getmansky, and Pelizzon (2010), in line with the asset pricing perspective proposed by Bekaert and 
Harvey (1995), to analyze the exposure of hedge fund indices with a factor model based on regime switching, where non-linearity in the exposure is captured by factor loadings that are state dependent. The univariate Markov switching (MS) factor models were used, where both the conditional mean and volatility are regime-switching. Because the MS approach takes into account volatility switching in the market risk factor, the factor loading estimates are unbiased. Furthermore, the MS switching regime framework allows to calculate time-varying risk exposure, and provides an accurate representation of the left-hand tail of the return distribution as it accounts for infrequent and shortlived events. This facilitates the identification of patterns and in conjunction with the use of conditional information, that the Markov chain allows, is especially advantageous in forecasting.

Additionally, a Markov switching model can include nonlinearity in the residuals and in the intercept coefficient to capture additional nonlinearities. The regime switching model can also be extended to a multifactor model that takes into account multiple factors that affect hedge fund returns. Financial literature has indicated that hedge fund returns can be affected by more than one factor. Goetzmann et al. (2006) showed that an optimal strategy for hedge funds might be selling out-of-the money puts and calls, ensuring that during normal and up markets, hedge fund managers obtain a positive cash flow, and thus have a large exposure in extreme negative events. Similarly, Billio et al. (2010) concluded that hedge funds exhibit significant nonlinear exposure not only to the market risk factor but also to Fama and French's (1993) size and value factors, bonds, currencies, commodities, volatility, credit and term spreads.

Billio et al. (2010) proposed a multifactor beta switching model that allowed for "the detection of the exposure of hedge fund indices to different factors conditional on the state that characterizes the market index factor" and "the exposure of hedge fund indexes with a factor model based on regime switching, where non-linearity in the exposure is captured by factor loadings that are state dependent." Their analysis 
focused on selected hedge fund strategy classifications, as different factors are relevant to different styles.

In this paper, the results of Billio et al. (2010) were extended, and the models proposed follow a three-state Markov switching process. The states represent the states of the global economy and were estimated using the MSCI World Index, as the MSCI World Index was found to be very accurate in picking up all major crises when using a two-state Markov switching-regime model (Olivares, Reus, Seco and Zagst (2011)). As the models are all regime switching models, they allow for nonlinearity in residuals and nonlinear exposure to market factors.

Initially, the state dependent exposure of hedge fund indices to the MSCI World Index is assessed in the univariate case, which is then extended the multivariate case. In the multivariate model, the role of macroeconomic factors in modeling hedge fund returns is sought, as the role of macroeconomic factors in this context is often neglected. This is compared with the multivariate model using only financial factors. Finally, in order to capture additional nonlinearities, without making the model cumbersome, the multivariate model was extended to a multivariate quadratic model, and macroeconomic and financial variables were tested together.

This paper is organized as follows: Section 2 describes the data, Section 3 describes the states and the models, Section 4 gives the results and an analysis of the estimation, Section 5 concludes.

\section{Data}

The data are monthly, and cover a 257 month period between January 1990 and May 2011, and were obtained from Hedge Fund Research Inc. (henceforth HFRI). The HFRI monthly indices are a series of benchmarks designed to reflect hedge fund industry performance by constructing equally weighted composites of constituent funds, as reported 
by the hedge fund managers listed within the HFR Database. The scope of the paper is limited, and thus the focus is on two composite indices, the Fund Weighted Composite (with over 2000 constituent funds) and the Fund of Funds Weighted Composite (with over 650 constituent funds), as well as two specific strategy classifications, Emerging Markets (Total), and Macro (Total). ${ }^{1}$ This is important in selecting the appropriate market index factor, as well as other risk factors.

As a market factor the MSCI World Index was used, which contains monthly data since its base date, December 31, 1969. Olivares, Reus, Seco and Zagst (2011) showed that when using a two-state Markov switching-regime model, the MSCI World Index was very accurate in picking up all major crises.

In computing the states, the discrete returns of MSCI index were used since its base date. In the computation of the models however, all returns, HFRI and MSCI, are discrete and net of the risk free rate (3-month US treasury bill rate), and can be shown by

$$
Y_{t}=\frac{H F R I_{t}-H F R I_{t-1}}{H F R I_{t-1}}-r f_{t}, \quad X_{t}=\frac{M S C I_{t}-M S C I_{t-1}}{M S C I_{t-1}}-r f_{t}
$$

where, at time $t=1,2, \ldots, 257, H F R I_{t}$ is the observation (price) of an HFRI index, $Y_{t}$ is the net returns of that strategy index, $M S C I_{t}$ is the observation (price) of the MSCI World index, $X_{t}$ is the net returns of the MSCI World index, and $r f_{t}$ is the risk-free rate.

\section{Markov Regime Switching Models}

\section{$3.1 \quad$ States}

To model the net returns of hedge funds, a discrete-time Markov switching model was used with $N=3$ regimes (states). The three regimes represent three likely states of the market: normal, crisis, and up-market. To solve for the most likely state sequence

${ }^{1}$ For more information regarding the HFRI strategy classifications see https: / /www.hedgefundresearch.com/index.php?fuse=indices-new\&1326249885\#2886 
(the most likely state of the market at time $t$ ), the discrete-time MSCI World Index returns, $X_{t}$, were used to estimate the following model

$$
X_{t}=\mu\left(S_{t}\right)+\sigma\left(S_{t}\right) \varepsilon_{t}
$$

where $S_{t}$ is the state at time $t, \mu$ is the mean and $\sigma$ is the standard deviation of $X_{t}$ conditional on $S_{t}$. The probability of remaining in a state, or changing states can be given by the transition matrix

$$
P_{M S C I}=\left(\begin{array}{ccc}
p_{11} & p_{21} & p_{31} \\
p_{12} & p_{22} & p_{32} \\
p_{13} & p_{23} & p_{33}
\end{array}\right)
$$

where $p_{11}=1-p_{21}-p_{31}, p_{22}=1-p_{12}-p_{32}$, and $p_{33}=1-p_{13}-p_{23}$. The probability of staying in the same regime is given by $p_{11}, p_{22}, p_{33}$. The system does not have a long memory and and the observations $\left(X_{t}\right)$ do not depend on the previous states, or the observations given the states at that time,$\left(S_{t}\right)$. The total probability is

$$
p\left(S^{T}, X^{T}\right)=p\left(S_{1}\right) \prod p\left(S_{t} \mid S_{t-1}\right) \prod p\left(X_{t} \mid S_{t}\right) .
$$

Equation 1 and the transition matrix are estimated using a generalized case of an Expectation Maximization algorithm, the Baum-Welch forward-backward algorithm. With the estimated values for equation 1 and the transition matrix, the unknown parameters in the hidden Markov chain can then be estimated with the dynamic programming algorithm, the Viterbi algorithm, yielding estimates of the most likely state sequence. 


\subsection{Univariate Regime Switching Model}

To begin, it is important to assess the exposure of each hedge fund strategy's returns (Emerging Markets, Funds, Funds of Funds, and Macro) to the market index factor (the MSCI World Index). To do this a simple univariate model was used that can be expressed as

$$
Y_{t}=\alpha\left(S_{t}\right)+\beta\left(S_{t}\right) X_{t}+\epsilon\left(S_{t}\right)
$$

where $\alpha$ and $\beta$ are both dependent on the state at time $t, S_{t}$.

\subsection{Multivariate Regime Switching Models}

The aim here is to evaluate how well hedge fund returns can be modeled using macroeconomic variables versus using financial variables, and which variables, economic and financial, are the most significant, ultimately testing how well these two sets of factors model hedge fund returns when used together. Furthermore, two models are considered: multivariate, and multivariate quadratic. The multivariate quadratic model extends the original multivariate model to detect non-linear exposure in variables.

\subsubsection{Macroeconomic Variables}

A comprehensive set of macroeconomic variables, were used including countercyclical, procyclical and structural variables. Hamilton (1989) used a Markov switching technique applied to postwar U.S. real GNP, and showed that "the periodic shift from a positive growth rate to a negative growth rate is a recurrent feature of the U.S. business cycle, and indeed could be used as an objective criterion for defining and measuring economic recessions." Hence, as a procyclical variable in this model, the change in U.S. real GNP2 ${ }^{2}$, was included. Two strong procyclical variables, consumption, and investment, were also included, where the change in consumption was measured by the

${ }^{2}$ Seasonally adjusted. 
change in the Personal Consumption Expenditure Price Index (henceforth abbreviated PCE) and the change in investment was measured by the change in the Gross Private Domestic Investment Chain-type Price Index ${ }^{3}$ (henceforth abbreviated GPDI). ${ }^{4}$ As a counter-cyclical variable, the US unemployment rate was used, and as a structural variable, the monthly average of the Federal Reserve's federal funds rate, was used as the interest rate. The monthly percentage rate inflation in the US CPI was also included. It should be noted that, by definition, real GNP is corelated to consumption and the nominal interest rate is corelated to the rate of inflation, however, this possible issue of multicolinearity was addressed in the method of estimation.

\begin{tabular}{|c|c|c|}
\hline Variable & Definition & Abbreviation \\
\hline \hline$E_{1}$ & Change in real GNP & dGNP \\
\hline$E_{2}$ & Unemployment & $\mathrm{U}$ \\
\hline$E_{3}$ & Inflation & $\pi$ \\
\hline$E_{4}$ & Change in Consumption (dPCE) & $\mathrm{dC}$ \\
\hline$E_{5}$ & Change in Investment (dGPDI) & $\mathrm{dI}$ \\
\hline$E_{6}$ & Interest rate (federal funds rate) & $\mathrm{i}$ \\
\hline
\end{tabular}

Table 1: Economic Variables

The Multivariate Regime Switching Model To assess the linear exposure to each macroeconomic factor within each state and using the same notation as in equation 2, the univariate case, this model is defined as

$$
Y_{t}=\alpha\left(S_{t}\right)+\beta\left(S_{t}\right) X_{t}+\gamma_{k}\left(S_{t}\right) E_{t k}+\epsilon\left(S_{t}\right)
$$

where there are $k=6$ factors, $E$, at time $t$, and $\gamma$ is the state-dependent parameter estimate for each of those factors. The list of factors and the corresponding variable is shown in Table 1.

${ }^{3}$ The data for the Gross Private Domestic Investment Chain-type Price Index were obtained from the Federal Reserve Economic Data (FRED) website, http://research.stlouisfed.org/fred2/categories/21.

${ }^{4}$ US real GNP and GPDI had quarterly data, thus piecewise constant interpolation was used to calibrate the model. For more thorough treatment of this see Gordon and Vlavonou (2012). 
The Quadratic Regime Switching Model Determining the linear as well as the quadratic exposure to each macroeconomic factor within each state, the model can be expressed as

$$
Y_{t}=\alpha\left(S_{t}\right)+\beta_{t, 1}\left(S_{t}\right) X_{t}+\beta_{t, 2}\left(S_{t}\right) X_{t}^{2}+\gamma_{t, 1, k}\left(S_{t}\right) E_{t k}+\gamma_{t, 2, k}\left(S_{t}\right) E_{t k}^{2}+\epsilon\left(S_{t}\right)
$$

where the notation is the same as (3).

\subsubsection{Financial Variables}

Billio et al. (2010) concluded that Hedge Funds exhibit significant non-linear exposure to the S\&P 500, Fama and French's (1993) size and value factors, bonds, currencies, commodities, volatility, credit and term spreads. In light of their findings, the variables included were, the S\&P 500 returns, the change in the price of gold bullion, a credit spread (the difference between Moody's BAA and AAA indices), the term spread (US 10-year Treasury bills and minus 6-month LIBOR), a large-small factor (the difference between the Russell 1000 and the Russell 2000 indices), a value-growth factor (the difference between the Russell 1000 Value and Growth indices), the change in volatility index, VIX, from the Chicago Board Options Exchange $(\mathrm{CBOE})^{5}$, the Fama French Momentum Factor (MOM) ${ }^{6}$, Barclays U.S. Aggregated Government Credit Index, Barclays U.S. Aggregated Government Bond Index.

Multivariate Regime Switching Model To assess the linear exposure to each financial factor within each state and using the same notation as in equation 2, the univariate

\footnotetext{
${ }^{5}$ All historical VIX data used were computed using the revised methodology and were obtained from the CBOE.

${ }^{6}$ The Fama French Momentum Factor was obtained from the website of Kenneth R. French.
} 


\begin{tabular}{|c|c|c|}
\hline Variable & Definition & Abbreviation \\
\hline \hline$F_{1}$ & Retruns of the S\&P 500 & dSP \\
\hline$F_{2}$ & Change in Price of Gold Bullion & dGold \\
\hline$F_{3}$ & Term Spread & TS \\
\hline$F_{4}$ & Credit Spread & CS \\
\hline$F_{5}$ & Large-Small Factor & LS \\
\hline$F_{6}$ & Value-Growth Factor & VG \\
\hline$F_{7}$ & Change in Volatility Index & dVIX \\
\hline$F_{8}$ & Fama French Momentum Factor & MOM \\
\hline$F_{9}$ & Barclays Government Credit & BGC \\
\hline$F_{10}$ & Barclays Government Bond & BGB \\
\hline
\end{tabular}

Table 2: Financial Variables

case, this model is defined as

$$
Y_{t}=\alpha\left(S_{t}\right)+\beta_{t, 1}\left(S_{t}\right) X_{t}+\delta_{t, 1, l}\left(S_{t}\right) F_{t l}+\epsilon\left(S_{t}\right)
$$

where there are $l=10$ factors, $F$, at time $t$, and $\delta$ is the state-dependent parameter estimate for each of those factors. The list of factors and the corresponding variable is shown in Table2.

Quadratic Regime Switching Model Determining the linear as well as the quadratic exposure to each financial factor within each state, the model can be expressed as

$$
Y_{t}=\alpha\left(S_{t}\right)+\beta_{t, 1}\left(S_{t}\right) X_{t}+\beta_{t, 2}\left(S_{t}\right) X_{t}^{2}+\delta_{t, 1, k}\left(S_{t}\right) F_{t k}+\delta_{t, 2, k}\left(S_{t}\right) F_{t k}^{2}+\epsilon\left(S_{t}\right)
$$

where the notation is the same as (5).

\subsubsection{Financial and Macroeconomic Variables}

In order to assess, out of both sets of risk factors, financial and macroeconomic, which are the most pertinent when used together, both sets of factors are included. To allow for nonlinear risk exposure in the variables, the model estimated is a multivariate quadratic 
one and takes the form

$$
\begin{aligned}
Y_{t}= & \alpha\left(S_{t}\right)+\beta_{t, 1}\left(S_{t}\right) X_{t}+\beta_{t, 2}\left(S_{t}\right) X_{t}^{2}+\gamma_{t, 1, k}\left(S_{t}\right) E_{t k}+\gamma_{t, 2, k}\left(S_{t}\right) E_{t k}^{2} \\
& +\delta_{t, 1, l}\left(S_{t}\right) F_{t l}+\delta_{t, 2, l}\left(S_{t}\right) F_{t l}^{2}+\epsilon\left(S_{t}\right)
\end{aligned}
$$

where the variables are the same as those used in equations 4 and 5 .

\section{Results and Analysis}

\section{Descriptive Statistics}

To show the changes in prices over time, the simplifying assumption that each hedge fund index started at $\$ 100$ was made and the prices were graphed over time. Referring to Table 3, it is evident that the mean returns of Fund of Funds (0.65) are significantly lower than those of Emerging Markets (1.17) and Macro (1.07), whereas Fund Weighted (0.96) lies in between. The standard deviation of returns is significantly higher for Emerging Markets (4.14), followed by Macro (2.22), Fund Weighted (2.02) and finally Fund of Funds (1.70). Emerging Markets, Fund Weighted, and Fund of Funds have returns that are left-skewed, while those of Macro are right-skewed. In terms of kurtosis, all returns have excess kurtosis, indicating leptokurtic distributions. The returns of the Macro (0.82) strategy have the lowest excess kurtosis, followed by those of Fund Weighted (2.63), and finally Emerging Markets (3.78) and Fund of Funds (3.99) have the most excess kurtosis making them the most fat-tailed.

\begin{tabular}{|l|r|r|r|r|r|r|}
\hline Strategy & Max & Min & Mean & Std Dev & Skew & Ex.Kurtosis \\
\hline \hline 1-Emerging Markets & 14.8 & -21.02 & 1.17 & 4.14 & -0.88 & 3.78 \\
\hline 2-Fund Weighted & 7.65 & -8.70 & 0.96 & 2.02 & -0.73 & 2.63 \\
\hline 3-Fund of Funds & 6.85 & -7.47 & 0.65 & 1.70 & -0.71 & 3.99 \\
\hline 4-Macro & 7.88 & -6.40 & 1.07 & 2.22 & 0.45 & 0.82 \\
\hline
\end{tabular}

Table 3: Descriptive Statistics of Returns

Recalling that net returns were defined as returns less the 3-month US treasury bill 


\begin{tabular}{|l|c|c|c|c|c|c|}
\hline Strategy & Max & Min & Mean & Std Dev & Skew & Ex. Kurtosis \\
\hline \hline 1-Emerging Markets & 9.58 & -25.91 & -2.43 & 4.71 & -0.81 & 2.41 \\
\hline 2-Fund Weighted & 5.01 & -13.59 & -2.63 & 2.76 & -0.40 & 0.65 \\
\hline 3-Fund of Funds & 3.18 & -12.36 & -2.94 & 2.48 & -0.20 & -0.11 \\
\hline 4-Macro & 4.87 & -11.4 & -2.53 & 2.93 & -0.12 & -0.17 \\
\hline
\end{tabular}

Table 4: Descriptive Statistics of Net Returns

\begin{tabular}{|c|c|c|c|c|c|c|}
\hline & Max & Min & Mean & Std Dev & Skew & Ex. Kurtosis \\
\hline \hline MSCI world & 14.27 & -19.05 & 0.62 & 4.32 & -0.56 & 1.64 \\
\hline
\end{tabular}

Table 5: Descriptive Statistics of MSCI World Index Returns

rate, and referring to Table 4, it is clear that all mean net returns are negative, the most negative being those of Fund of Funds (-2.94), followed closely by Fund Weighted (-2.63), Macro (-2.53) and Emerging Markets (-2.43). The net returns however, of Emerging Markets are the most volatile (4.71), and the least volatile for Funds of Funds (2.48), followed by Fund Weighted (2.76), and Macro (2.93). All strategies have net returns that are right skewed, the most skewed being those of Emerging Markets (-0.81), followed by Fund Weighted (-0.40), Fund of Funds (-0.20) and Macro (-0.12). With respect to kurtosis, the excess kurtosis of Emerging Market's (2.41) net returns is the highest, indicating leptokurtic distribution, whereas Fund Weighted (0.65) has less positive excess kurtosis and would have only slightly fatter tails than the Gaussian distribution. With Fund of Funds (-0.11) and Macro (-0.17) having negative excess kurtosis, their distributions would be platykurtic.

The descriptive statistics of the MSCI World Index returns can be seen in Tables 5 and 6 , where the statistics in Table 6 are computed with data starting from January 1972, the base date for the 3-month US treasury bill. The MSCI World returns since December 1969 were used to compute the states, and the returns net of the risk-free rate were used in the univariate (equation 2) and multivariate models (equation 5).

\begin{tabular}{|c|c|c|c|c|c|c|}
\hline & Max & Min & Mean & Std Dev & Skew & Ex. Kurtosis \\
\hline \hline MSCI world & 10.77 & -25.41 & -4.91 & 5.47 & -0.40 & 0.80 \\
\hline
\end{tabular}

Table 6: Descriptive Statistics of Net MSCI World Index Returns 


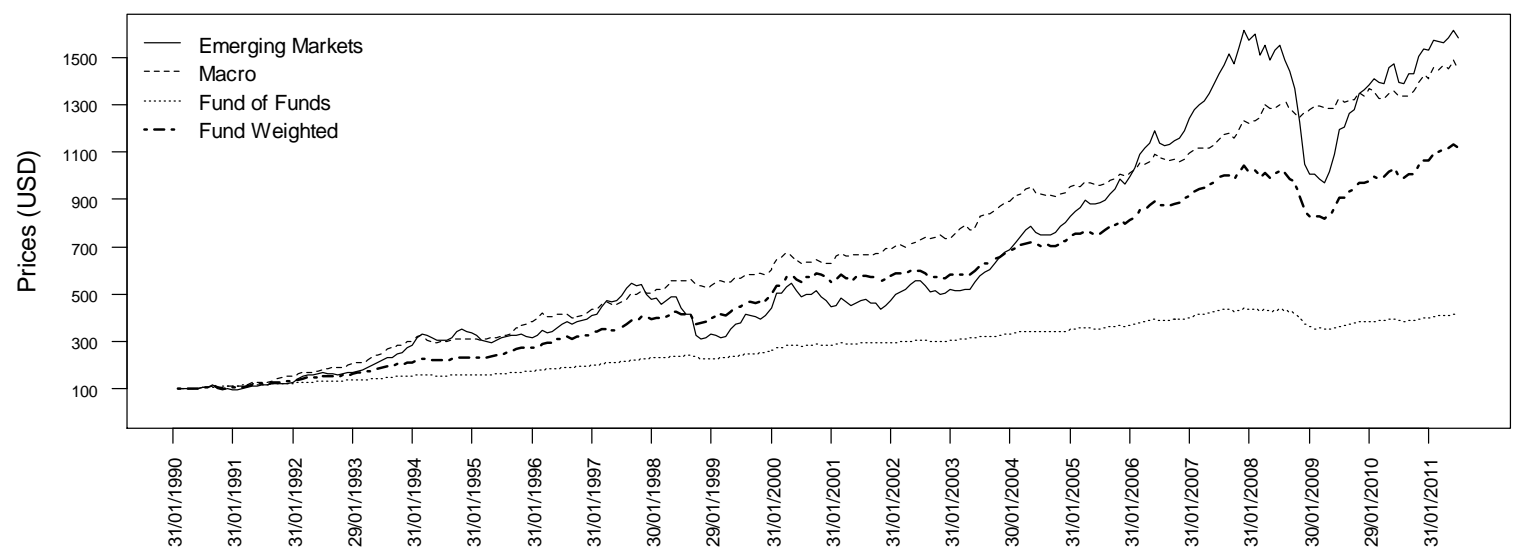

Figure 1: Prices of HFRI Indices over time

\subsection{States}

To ensure accuracy in the detection of states, although the data from HFRI begins at 1990, the states of the market where computed initially with the discrete returns of the MSCI World Index since its base date, December 31, 1969. Using the discrete returns of the MSCI World index, $X_{t}$, and the HiddenMarkov package in $\mathrm{R}$, assuming an underlying Gaussian distribution, the Baum-Welch algorithm was used to estimate the distribution parameters in equation 1, (shown in Table 7) and the transition matrix below. The crisis state seems to be characterised by $S_{2}$ and $S_{3}$ seems to represent the strong up-market transition, just before normalizing to a strong and healthy normal market, $S_{1}$.

\begin{tabular}{|c|c|c|c|}
\hline & $S_{1}$ & $S_{2}$ & $S_{3}$ \\
\hline \hline$\mu$ & 1.0959 & -1.6167 & 7.5116 \\
\hline$\sigma$ & 2.8715 & 5.6937 & 1.8220 \\
\hline
\end{tabular}

Table 7: Estimation of Distribution Parameters

$$
P_{M S C I}=\left(\begin{array}{lll}
0.9363 & 0.0637 & 0.0000 \\
0.0000 & 0.8386 & 0.1614 \\
0.9231 & 0.0769 & 0.0000
\end{array}\right)
$$


The state probabilities can be shown as

$$
\begin{aligned}
& P\left(S_{1}\right)=0.7008 \\
& P\left(S_{2}\right)=0.2711 \\
& P\left(S_{3}\right)=0.0281 .
\end{aligned}
$$

Referring to Tables 5 and 7, the crisis state is characterized by a much lower mean (-1.62) and a higher volatility (5.69), whereas before normalizing, the strong up-market transition state is characterized by the highest mean (7.51) and the lowest volatility (1.82), and the normal state is characterized by a mean (1.10) slightly higher than the average mean , and volatility (2.87) more than one third lower than the average volatility (4.32).

Looking at the transition matrix and the state probabilities, it is clear that the normal state, $S_{1}$ is the most probable $(70.08 \%)$, with a $93.63 \%$ probability of remaining in it, and a $6.37 \%$ probability of going into the crisis state. The crisis state, $S_{2}$, is less probable, $(27.11 \%)$, with an $83.86 \%$ probability of remaining in the same regime the next month, and a $16.14 \%$ probability of going into the peak up-market transition state. The up-market state is very transient, with only a $2.81 \%$ probability of occurring, zero probability of remaining in the same state, and a $92.31 \%$ probability of going into a normal state.

The estimated transition matrix and distribution parameters were then used in the Viterbi algorithm to estimate the most probable state sequence. This state sequence can be seen in Figures 2 and 4, where it is evident that the identification of states is rather accurate. The 1960s were characterized by unprecedented growth which then tapered off, and the 1970s opened with a recession in 1970. The model detects this 


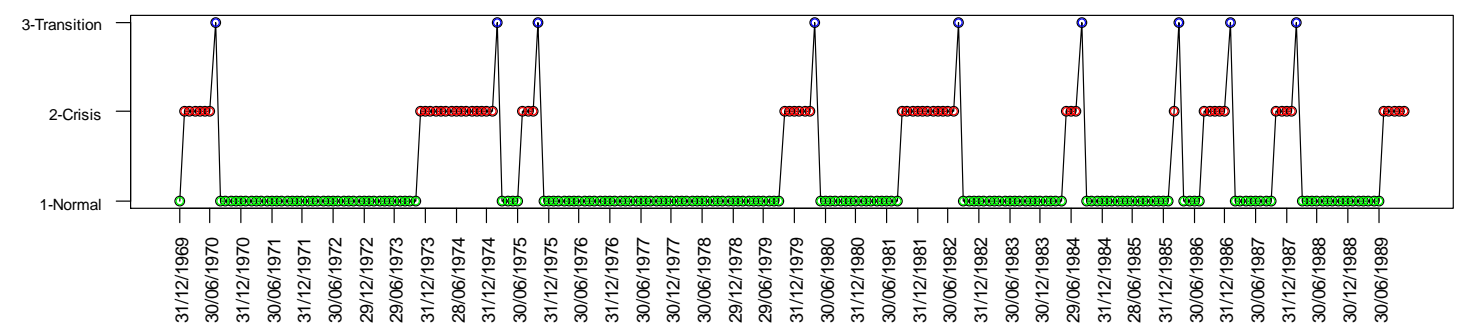

Figure 2: States from December 1969 to December 1989

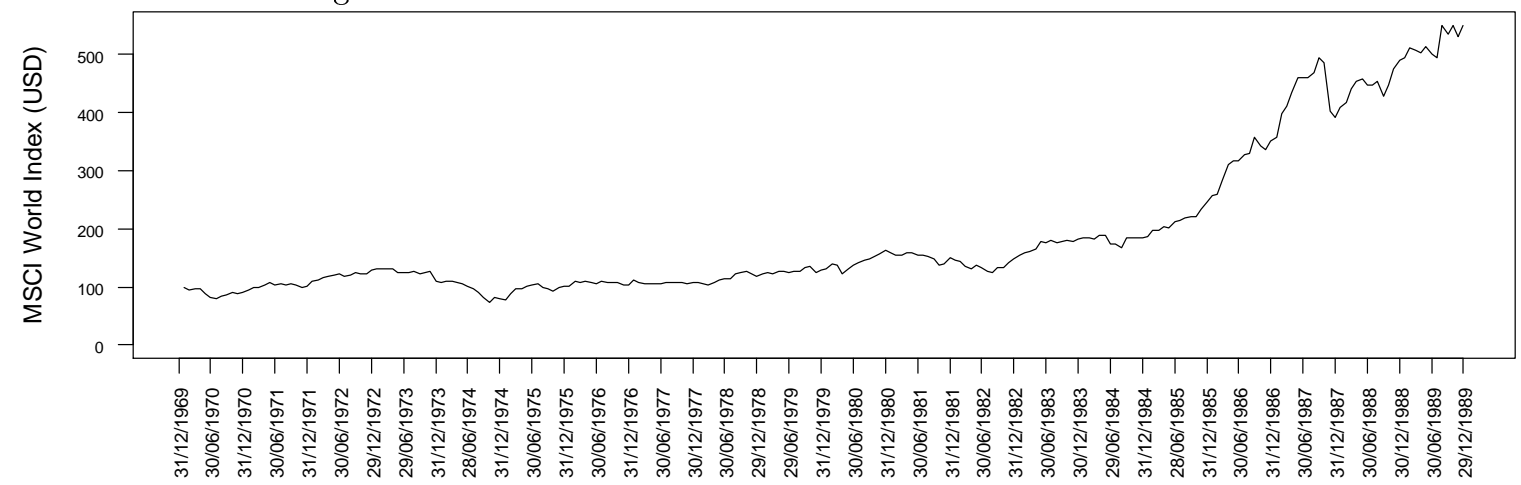

Figure 3: MSCI World Index from December 1969 to December 1989

shock, followed by the 1973 oil crisis, along with the 1973-1974 stock market crash and the secondary banking crisis in the UK. The 1979 secondary oil crisis is also detected in addition to the contraction of world trade in 1981. Black Monday in 1987 and the US Savings and Loan crisis starting in 1989, as well as the collapse of the asset price bubble in Japan are also identified. The model also correctly captures the Russian financial crisis in 1998, the burst of the dot-com bubble, extending through to September 11, 2001 and the ensuing market downturn. At the end of 2007 the model captures the collapse of the US housing bubble and the ensuing financial crisis that lasted until mid 2009, although the reverberations continued to be felt. The European sovereign debt crisis in 2010 was also correctly identified. The regimes were as predicted, and it can be seen that after all periods of crisis, there is a transitional up-market period before normalizing. 


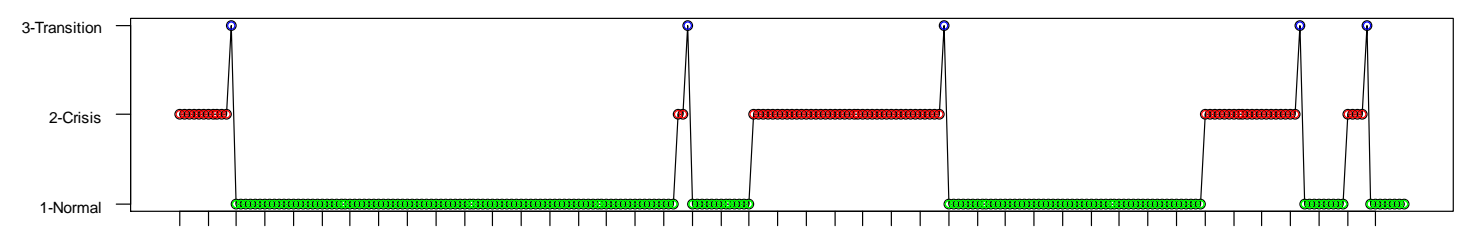

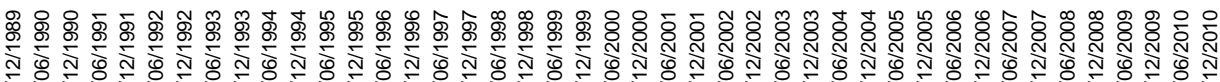

겅

Figure 4: States from December 1989 to May 2011

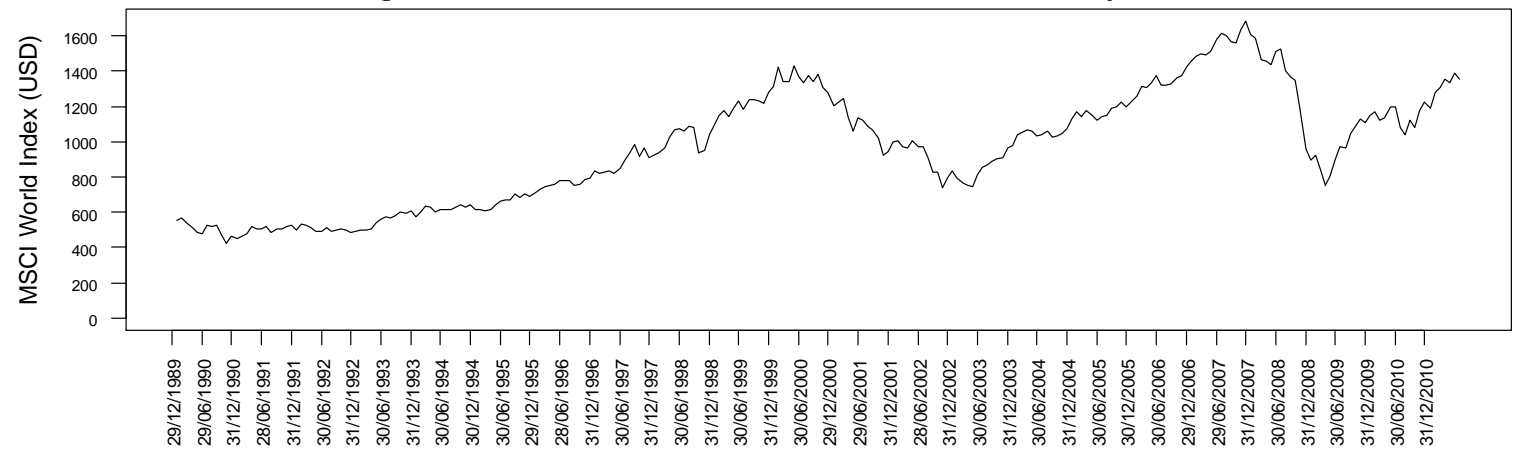

Figure 5: MSCI World Index from December 1989 to May 2011

\subsection{Univariate Regime Switching Model}

The univariate model shown in equation 2, was estimated using the estimated state sequence (above), and the results (estimates, standard errors, t-statistics, and $p$-values) can be found in Table 8 in the Appendix. All parameters are significant at the $5 \%$ level, with the exception of $\alpha_{1}$ and $\alpha_{2}$ for Emerging Markets. Overall, it can be seen that Emerging Markets exhibit the most exposure to the market factor index at any given state. Whereas it is evident that the most exposure to the MSCI World Index can be witnessed during up-market states, followed by normal states. Finally, during states of crisis, although the exposure is much higher for Emerging Markets, each fund style exhibits the least relative exposure to the market factor index. It should be noted however, that in total there are 14 observations of up-market state occurrences, nine instances from December 31, 1969 until December 29, 1989 and five such instances 
from January 31, 1990 until May 31, 2011. Since the base date of the HFRI Indices is January 1990, the lack of observations implies that the estimates of exposure to a factor in the up-market state are not reliable.

The switching regime beta estimates have been plotted over time and can be seen in Figure 6.

\subsection{Multivariate Regime Switching Model}

In this analysis, to limit the list of factors, backward elimination was used. In each model, all factors to be assessed were included and those with the highest $p$-values were eliminated sequentially to arrive at the final combination of factors which yielded the highest adjusted- $R^{2}$. Thus, despite the number of factors included initially, this method allowed models to be the least cumbersome possible, and also dealt with the problem of multicollinearity (as previously mentioned, between real GNP and consumption, and between the nominal interest rate and inflation).

Additionally, all equations $3,4,5,6$, and 7 were estimated with and without an intercept parameter, $\alpha\left(S_{t}\right)$, and it was found that for all states and for all hedge fund strategies, the models all had significantly higher adjusted- $R^{2}$ values when estimated without an intercept coefficient. Therefore, in the remainder of this paper, when referring to the multivariate and multivariate quadratic models, the following models were 

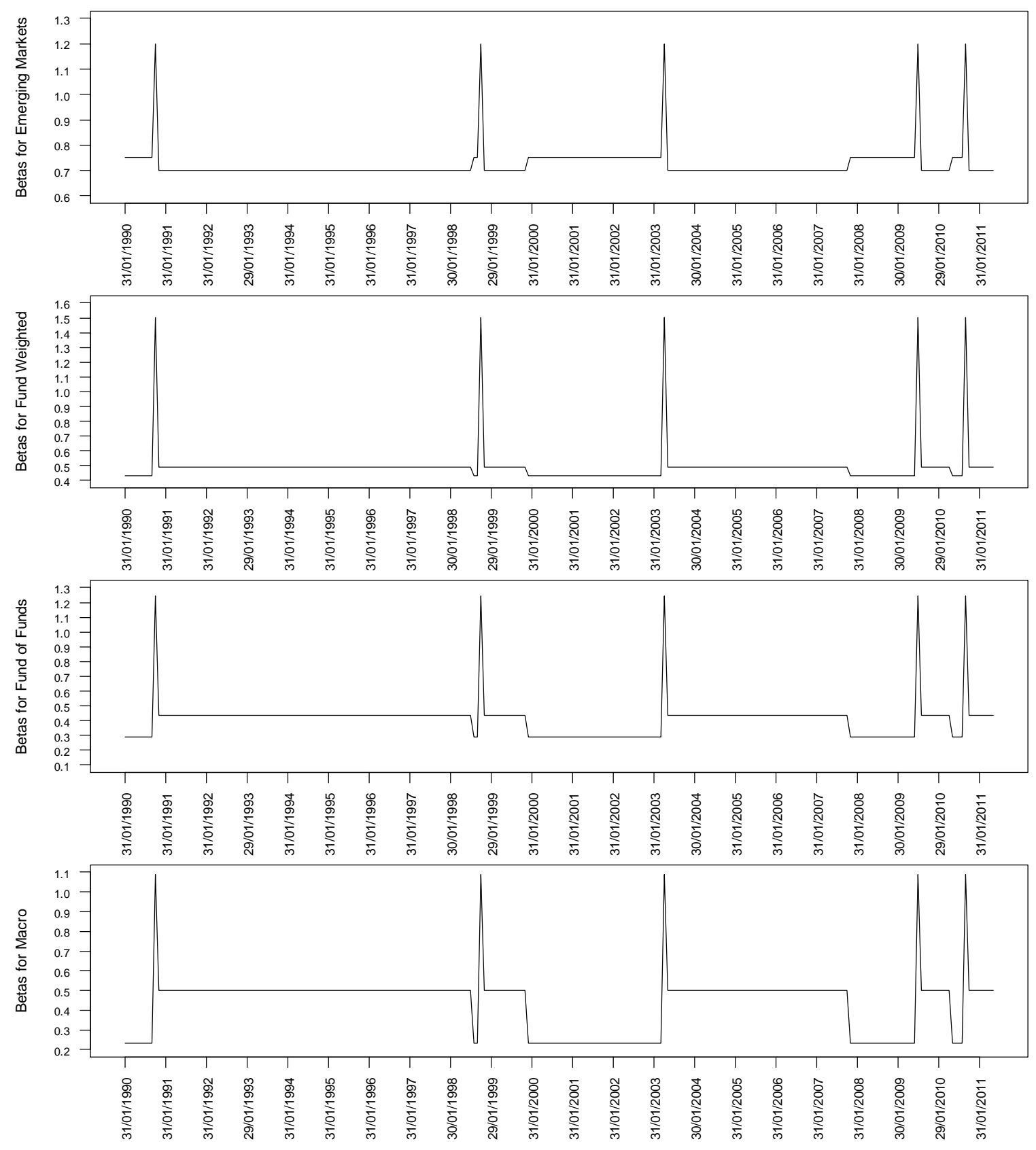

Figure 6: Switching Beta Estimates for Each Index 
estimated

$$
\begin{aligned}
Y_{t}= & \beta\left(S_{t}\right) X_{t}+\gamma_{k}\left(S_{t}\right) E_{t k}+\epsilon\left(S_{t}\right) \\
Y_{t}= & \beta_{t, 1}\left(S_{t}\right) X_{t}+\beta_{t, 2}\left(S_{t}\right) X_{t}^{2}+\gamma_{t, 1, k}\left(S_{t}\right) E_{t k}+\gamma_{t, 2, k}\left(S_{t}\right) E_{t k}^{2}+\epsilon\left(S_{t}\right) \\
Y_{t}= & \beta_{t, 1}\left(S_{t}\right) X_{t}+\delta_{t, 1, l}\left(S_{t}\right) F_{t l}+\epsilon\left(S_{t}\right) \\
Y_{t}= & \beta_{t, 1}\left(S_{t}\right) X_{t}+\beta_{t, 2}\left(S_{t}\right) X_{t}^{2}+\delta_{t, 1, k}\left(S_{t}\right) F_{t k}+\delta_{t, 2, k}\left(S_{t}\right) F_{t k}^{2}+\epsilon\left(S_{t}\right) \\
Y_{t}= & \beta_{t, 1}\left(S_{t}\right) X_{t}+\beta_{t, 2}\left(S_{t}\right) X_{t}^{2}+\gamma_{t, 1, k}\left(S_{t}\right) E_{t k} \\
& \quad+\gamma_{t, 2, k}\left(S_{t}\right) E_{t k}^{2}+\delta_{t, 1, l}\left(S_{t}\right) F_{t l}+\delta_{t, 2, l}\left(S_{t}\right) F_{t l}^{2}+\epsilon\left(S_{t}\right) .
\end{aligned}
$$

\subsubsection{Macroeconomic Variables}

Here it is important to note that equation 8 was tested against two variations using all four hedge fund strategies. One variation was using the replacing unemployment and inflation with the change in unemployment and the change in inflation, respectively. The other variation included unemployment, inflation, change of unemployment, and change in inflation. After comparing the adjusted- $R^{2}$ for all models, under all states, using all four hedge fund indices, it was clear that the difference in adjusted- $R^{2}$ between equation 8 and its two variations was negligible. Thus, as was initially proposed in equation 8 , the rate of unemployment and the rate of inflation (and not their respective changes) were included in the analysis.

When estimating equation 8 , in both normal and crisis states, the returns of all HFRI strategies exhibited significant negative exposure at the 0.01 percent level of significance to $i$, the monthly average of the Federal Reserve's federal funds rate used as the interest

rate. Indeed, increases in the interest rate imply higher borrowing costs, and tend to dampen investment. 
Also, in both normal and crisis states, the returns of all HFRI strategies exhibited significant positive exposure to the MSCI World Index at the 0.1 percent level of significance; except the returns of the Macro strategy during times of crisis, where the level of significance was 6.2 percent. The steady positive exposure to the MSCI World Index may be indicative of the positions of hedge funds taken in countries other than the United States (exposure abroad). Macro strategies tend to be based within the United States, hence an international indicator of crises could be slightly less pertinent.

Inflation, $\pi$, was found to be significant at the 5 percent level of significance for all strategies during normal times, except for Funds of Funds where inflation was not selected as a pertinent factor. In times of crisis however, the exposure to inflation was insignificant enough to be eliminated from all models.

The change in Gross Private Domestic Investment, I, was found to be negatively related to returns and significant at the 10 percent level of significance for all strategies during normal times, except for the Emerging Markets strategy which exhibited insignificant exposure. In times of crisis however, similar to inflation, the exposure to investment was insignificant enough to be eliminated from all models.

The level of consumption spending, $C$, as measured by the Personal Consumption Expenditure Price Index, was eliminated as a pertinent factor for all strategies during normal times. Nevertheless, in times of crisis, consumption was not eliminated through the process of backward elimination (for all strategies except Macro) yet it was found to be significant only for Funds of Funds $(0.8 \%)$.

Unemployment did not seem to be a pertinent factor, as exposure to unemployment was only found to be significant at the $5 \%$ level in normal times for Funds of Funds, and during crisis states at the $10 \%$ level for Emerging Markets and Macro.

Similarly, the change in GNP was also not found to be significant at the $10 \%$ level for the Fund Weighted Composite Index during times of crisis. 
Here it is important to note that there were very minor improvements in the adjusted$R^{2}$ when estimating the quadratic multivariate model (equation 9) in comparison to its simple multivariate counterpart (equation 8). Across strategies and across states, there were only minor improvements in the adjusted- $R^{2}$ that fluctuated between 0.3 and 3.8 percent, where the smallest change was when estimating Funds of Funds in normal times and the largest change when estimating the returns of Emerging Markets strategies also during normal times.

Exposure to the MSCI World Index was again found to be positive and significant at the 5 percent level for all strategies in both normal and crisis states. Whereas at the $10 \%$ level of significance, significant exposure to $\mathrm{MSCI}^{2}$ was found to be negative for Emerging Markets during periods of crisis, and positive for Macro strategies during normal times, although both values were very close to zero.

All strategies, at the 0.1 percent level of significance, exhibited significant negative exposure to the interest rate during periods of crisis. In normal states, significant negative exposure of all strategies to the interest rate was observed, at the 0.1 percent level for all strategies except Fund Weighted (8.9 percent).

Across all strategies during periods of crisis, positive exposure was observed to the squared change in GNP at the 2.5 percent level of significance, and no significant exposure was observed to the change in GNP at the $10 \%$ level. During normal states, at the $10 \%$ level of significance, Emerging Markets and Fund Weighted exhibited significant negative exposure to the change in GNP, whereas Fund Weighted and Macro displayed significant positive and negative relation respectively to $\mathrm{dGNP}^{2}$.

In normal states, Macro showed significant positive exposure to inflation at the 2.5 percent level, and Emerging Markets displayed significant positive quadratic exposure to inflation at the 1 percent level. Emerging Markets also exhibited significant positive exposure and significant negative quadratic exposure to inflation at the 5 percent level.

The level of personal consumption, $C$, was found to be significant at the 5 percent 
level, and positively related to all funds except Macro, during crisis states. Conversely, no significant exposure to $C$ or $C^{2}$ was observed during normal times at the $10 \%$ level.

The change in gross domestic private investment, $I$, was not the most pertinent factor. In normal states, Funds of Funds demonstrated negative exposure to $I$ significant at the 1 percent level, whereas Emerging Markets and Macro showed negative exposure to $I^{2}$ significant at the 5 percent level. Moreover, during periods of crisis, Emerging Market was the only strategy index to show any significant exposure to investment which, was positive and quadratic, at the 5 percent level.

Unemployment was found to be even less significant than in the simple multivariate case, being eliminated as a factor during the process of backward elimination.

\subsubsection{Financial Variables}

Multivariate Regime Switching Model When estimating the multivariate model (equation 10), the returns of all HFRI strategies in normal, $S_{1}$, and crisis, $S_{2}$, states consistently exhibited significant exposure, at the 10 percent level, to the following factors: monthly returns of the MSCI World Index, the returns of gold bullion, term and credit spreads, and the large-small factor. Although it should be noted that the exposure of Emerging Markets to the MSCI World Index was the largest and of the most significant, while the exposure of Macro was the least significant and of the smallest. This could be attributed to the trading strategies, since the MSCI World Index in a global index and Emerging Markets have the majority of their portfolio exposure in emerging markets. The exposure to gold is found to be significant and positive in both normal and crisis states for all strategies with the exception of Emerging Markets, indicating that the Emerging Markets portfolio may not be significantly exposed to changes in the price of gold. Term spreads, credit spreads and the Large-Small factor, were found to be positive and significant for all strategies (except for Macro which is discussed below), 
and the most significant for Fund Weighted and Fund of Funds. This is reasonable since those two indices encompass hedge funds which employ an array of strategies which may be dependent on the aforementioned three factors. The credit spread and Large-Small factor were not found to be significant however, for Macro during normal periods indicating a state contingent relationship.

Factors also found useful systematically in estimating returns were Barclays US Aggregate Government Credit Index, and Barclays US Aggregate Government Bond Index. In normal periods, all funds displayed positive exposure to Barclays US Aggregate Government Credit Index and negative exposure to Barclays US Aggregate Government Bond Index. During times of crisis, at the 0.1 percent level of significance, significant negative exposure was observed to Barclays US Aggregate Government Credit Index by all strategies with the exception of Funds of Funds that demonstrated the same significant negative exposure to Barclays US Aggregate Government Bond Index.

The Momentum factor (MOM) was found to be positive and significant at the 10 percent level of significance for all strategies in all states with the exception of Fund Weighted (which did not show exposure during periods of crisis) and Emerging Markets. This is not unreasonable, since the hedge funds which compose the Emerging Markets Index invest primarily outside the US and the Momentum Factor is based on portfolios composed of US stocks. ${ }^{7}$

The Value-Growth factor (VG) was found to be significantly negatively related to the returns of Fund Weighted and Funds of Funds during crisis states. In times of crisis, the difference between the Russell 1000 Growth Index and the Russell 1000 Value Index becomes larger which may explain the aforementioned state-dependent relationship. Furthermore, as mentioned previously, the Value-Growth factor is based on the Russell 1000 which, represents the US equity market, ${ }^{8}$ and thus may not be a pertinent factor

\footnotetext{
${ }^{7}$ For more details on the Momentum Factor see http://mba.tuck.dartmouth.edu/pages/faculty/ken.french/Data_Library/det_mom_factor.html. ${ }^{8}$ For more information on the Russell 1000 see http://www.russell.com/indexes/data/fact_sheets/us/russell_1000_index.asp.
} 
for Emerging Markets. Also, the equities which constitute the Russell 1000 Growth Index and the Russell 1000 Value Index may not necessarily be impacted enough by by movements in economic factors, which would explain why Macro did not show any significant exposure to the Value-Growth factor.

Of the least pertinent factors in estimating returns was $F_{1}$, the monthly returns of S\&P 500 and the change in VIX. This may have been because the monthly returns of the S\&P 500 are correlated with those of the MSCI World Index. Similarly, as a measure of the expected volatility of the S\&P 500 Index options, the change in VIX was also found not to be pertinent in estimating returns. This could be attributed to the strategies being assessed; as Macro strategies are based on the movements of economic variables and the ensuing effects on various markets and Emerging Market strategies are based primarily in markets outside the US, the S\&P 500 and the change in VIX are less pertinent in modeling the returns of these strategies.

Multivariate Quadratic Regime Switching Model Here it is important to note that there were minimal improvements in the adjusted- $R^{2}$ when estimating the quadratic multivariate model (equation 11) in comparison to its simple multivariate counterpart (equation 10). Only when estimating the returns of Macro strategy returns during times of crisis, did the adjusted- $R^{2}$ increase approximately 6 percent, otherwise, across strategies and across states, there were only minor improvements in the adjusted- $R^{2}$ that fluctuated between 0.3 and 1.9 percent. Furthermore, when estimating the quadratic multivariate model, singularities were produced when estimating the simple exposure to: the change in VIX, the Momentum factor, Barclays US Aggregated Government Credit Index, and Barclays US Aggregated Government Bond Index; thus, the aforementioned parameters could not be estimated. 
Again, it is found that when estimating (equation 11), the returns of all HFRI strategies in normal, $S_{1}$, and crisis, $S_{2}$, states consistently (with few exceptions) exhibited significant exposure at the 10 percent level, to the following factors: monthly returns of the MSCI World Index, the returns of gold bullion, term and credit spreads, and the large-small factor. The MSCI World Index was found to be significant at the 5 percent level for all strategies in both normal and crisis states, with the exception of Fund Weighted for which it was insignificant at the 10 percent level, during times of crisis. This seems to indicate that the relationship between the returns and the MSCI World Index is predominantly linear. Both the change in gold and the quadratic change in gold were found to be significant at the $5 \%$ level for all strategies during normal regimes. In crisis regimes, all strategies displayed, at the 5 percent level, significant exposure to gold, either positive or negative quadratic or both, indicating a strategy and statedependent degree of exposure. This state-dependent exposure may be to a higher degree (cubic, etc.) however, further research would be required to establish this.

All strategies, at the 5 percent level of significance, exhibited either positive exposure or negative quadratic exposure, or both to term spreads, in both normal and crisis states. To credit spreads however, the significant exposure was much less consistent across states and strategies.

In terms of exposure to the Large-Small factor (LS), all strategies in both normal and crisis states, displayed significant positive exposure to LS except, during times of crisis for Funds of Funds, and during normal times for Macro. Although certain strategies did indicate exhibit some quadratic exposure to LS, at the 10 percent level, this exposure was insignificant which, would seem to indicate that the relationship between the returns and LS is predominantly linear.

All strategies at the 10 percent level of significance, displayed significant positive quadratic exposure to Barclays US Aggregated Government Bond Index in both normal and crisis states, with the exception of Macro who did not show any significant exposure 
during times of crisis. At no time did any strategy demonstrate significant exposure to the Barclays US Aggregated Government Credit Index.

In crisis states, negative exposure and positive quadratic exposure were observed to VG for significant for Fund Weighted and Funds of Funds at the 5 percent level; both observed exposures for Emerging Markets were not significant at the 10 percent level and for Macro, the negative exposure to VG was also not significant at the 10

percent level. Moreover, for any strategy during normal periods, $\mathrm{VG}$ and $\mathrm{VG}^{2}$ did not survive after the backward elimination. These results indicate that the relationship to the Value-Growth factor is state-dependent and in crisis states there may be multiple degrees of exposure.

At the 5 percent level, significant positive quadratic exposure to the Momentum factor was witnessed in normal times by Fund Weighted and Funds of Funds, while significant negative quadratic exposure to MOM was shown by Emerging Markets. When selecting pertinent factors during states of crisis however, the Momentum factor was eliminated in the process of backward elimination.

Significant exposure to the returns of the S\&P 500 was only witnessed during normal times by all factors except Emerging Markets, and was observed to be very small positive and quadratic.

Similar to the simple multivariate case, the change in VIX was found be the least pertinent factor. Noting that, as previously mentioned, only the quadratic exposure to the change in VIX could be estimated, and in doing so, no significant exposure was found in either of the two regimes, normal or crisis, for any strategy.

\subsubsection{Financial and Macroeconomic Variables}

The results when estimating the multivariate quadratic regime switching model with both sets of factors, were consistent with the results when each set of factors was tested separately, yet far more informative. 
One of the most significant factors was the interest rate, $i$, represented by the monthly average of the Federal Reserve's federal funds rate. During normal states, all strategies exhibited negative quadratic exposure significant at the 5 percent level of significance, while in times of crisis, all funds displayed negative exposure to the interest rate significant at the 1 percent level. These results seem to indicate that the degree of exposure (linear or quadratic) of HFRI returns to the Federal Reserve's federal funds rate is in is largely state-dependent.

All strategies, with the exception of Macro, exhibited some negative exposure to the change in gross private domestic investment, $I$ and positive exposure to $I^{2}$, during times of crisis; the exposure however was not always significant at the 10 percent level. During normal times, negative quadratic exposure was observed by all strategies to the change in investment, significant at the 10 percent level for all except Funds of Funds. Indeed, this observed negative relationship can be explained by first recalling that GPDI consists of fixed investment and the change in private inventories. ${ }^{9}$ Hedge funds on the other hand, primarily trade securities and employ a variety of techniques, such as short selling, trend following etc., and hence benefit from times of high volumes and large changes in market volatility. Thus, when capital is directed toward fixed investments and private inventories instead of capital markets, the majority of hedge funds would not necessarily benefit.

Inflation and quadratic inflation were eliminated as factors during normal times although during times of crisis, all strategies, with the exception of Macro, demonstrated significant exposure to inflation at the 2.5 percent level. Furthermore all strategies except Funds of Funds, demonstrated significant quadratic exposure to inflation at the 2.5 percent level.

Only for Funds of Funds was unemployment found to be significant at the 10 percent level, exhibiting negative exposure during both normal (-0.915) and crisis (-4.098)

\footnotetext{
${ }^{9}$ More information on National Income Product Accounts can be obtained at http://www.bea.gov/national/pdf/nipaguid.pdf.
} 
states. Additionally, at the 5 percent level of significance, positive quadratic exposure to unemployment was observed for Funds of Funds during times of crisis.

The movements of financial factors and During the crisis state hedge funds tend to short risk and the "flight to quality" phenomenon is observed. During times of crisis, most capital flees emerging investors buy US dollars as well as gold and T-bills.

Emerging Markets displayed the most significant exposure during normal times to the credit spread (positive exposure) followed by the squared Momentum factor (negative exposure). In crisis states, Emerging Markets exhibited the most significant exposure to inflation and the change in Personal Consumption Expenditure, the exposure being positive in both cases. Overall, in times of crisis, Emerging Markets showed more significant exposure to macroeconomic factors than to financial factors, whereas during normal states the opposite was observed.

Macro exhibited the most significant exposure to the credit spread (negative exposure) followed by the squared Momentum factor (positive exposure) during normal times. During times of crisis, Macro strategies continued to display the most significant exposure to the credit spread (although the exposure was positive) and higher exposure was exhibited to the interest rate (negative) and $\mathrm{MOM}^{2}$ (negative). In both normal and crisis states, Macro showed more significant exposure to financial factors than to macroeconomic factors.

Fund Weighted displayed the most exposure to the credit spread( in both followed by the interest rate (negative and significant) during normal periods. In periods of crisis, Funds of Funds continued to exhibit the most exposure to the credit spread (positive and significant) followed by $\mathrm{MOM}^{2}$ (negative and significant). On the whole, Funds of Funds showed more significant exposure to financial factors than to macroeconomic factors in both normal and crisis states.

Funds of Funds exhibited the highest exposure to unemployment which was negative and significant, followed by $\mathrm{MOM}^{2}$ which was positive and significant. During periods 
of crisis, Funds of funds continued to display the most exposure to the unemployment rate (negative and significant) followed by the credit spread (positive and significant). Overall, Funds of funds exhibited the most significant exposure to financial variables during normal times, and equal significant exposure to both types of variables in times of crisis.

\section{Conclusions}

The MSCI World Index was used to detect the regimes of the market, assumed to be three, and was found to be relatively accurate in detecting significant global events. These states were used to assess state-dependent exposure of the returns of two HFRI composite indices (Fund Weighted and Fund of Funds) and two HFRI strategy classifications (Emerging Markets and Macro) to macroeconomic and financial factors. The exposure to each set of factors was tested separately, then jointly, and although certain nonlinearities were captured using a Markov switching model, in order to capture additional nonlinearities, the model was expanded to a multifactor quadratic model.

These results indicate that the exposure to a given factor is largely state dependent: the returns of different hedge fund indices exhibit exposure to different factors conditional upon the state of the global economy, the ensuing changes in economic indicators, and the changes in capital flows. Furthermore, macroeconomic factors were found to be significant in estimating the returns of hedge fund indices, and quadratic models using both financial and economic factors yield significantly better estimates. 


\section{Appendix}

\section{Univariate}

\begin{tabular}{|c|c|c|c|}
\hline Strategy & \multicolumn{3}{|c|}{ 1-Emerging Markets } \\
\hline \hline Variable & EsTIMATE & T-STAT (P-VALUE) & $\mathrm{SE}$ \\
\hline$\alpha_{1}$ & -0.204 & $-0.730(0.466)$ & 0.280 \\
\hline$\alpha_{2}$ & 0.176 & $0.352(0.726)$ & 0.499 \\
\hline$\alpha_{3}$ & -5.619 & $-3.356(0.044)$ & 1.674 \\
\hline$\beta_{1}$ & 0.702 & $10.994(0.000)$ & 0.063 \\
\hline$\beta_{2}$ & 0.752 & $12.588(0.000)$ & 0.060 \\
\hline$\beta_{3}$ & 1.201 & $4.840(0.017)$ & 0.248 \\
\hline \hline Strategy & \multicolumn{3}{|c|}{ 2-Fund Weighted } \\
\hline \hline Variable & EsTIMATE & T-STAT (P-VALUE) & $\mathrm{SE}$ \\
\hline$\alpha_{1}$ & -1.173 & $-8.825(0.000)$ & 0.133 \\
\hline$\alpha_{2}$ & -0.995 & $-3.250(0.002)$ & 0.306 \\
\hline$\alpha_{3}$ & -9.975 & $-61.166(0.000)$ & 0.163 \\
\hline$\beta_{1}$ & 0.489 & $16.143(0.000)$ & 0.030 \\
\hline$\beta_{2}$ & 0.435 & $11.874(0.000)$ & 0.037 \\
\hline$\beta_{3}$ & 1.502 & $62.158(0.000)$ & 0.024 \\
\hline \hline Strategy & \multicolumn{3}{|c|}{3 -Funds of Funds } \\
\hline \hline Variable & EsTIMATE & T-STAT (P-VALUE) & SE \\
\hline$\alpha_{1}$ & -1.729 & $-12.011(0.000)$ & 0.144 \\
\hline$\alpha_{2}$ & -1.746 & $-5.315(0.000)$ & 0.328 \\
\hline$\alpha_{3}$ & -9.375 & $-4.671(0.019)$ & 2.007 \\
\hline$\beta_{1}$ & 0.439 & $13.377(0.000)$ & 0.033 \\
\hline$\beta_{2}$ & 0.289 & $7.358(0.000)$ & 0.039 \\
\hline$\beta_{3}$ & 1.243 & $4.179(0.025)$ & 0.297 \\
\hline \hline Strategy & \multicolumn{3}{|c|}{4 -Macro } \\
\hline \hline Variable & EsTIMATE & T-STAT (P-VALUE) & SE \\
\hline$\alpha_{1}$ & -1.168 & $-5.98(0.000)$ & 0.195 \\
\hline$\alpha_{2}$ & -1.557 & $-3.68(0.000)$ & 0.423 \\
\hline$\alpha_{3}$ & -8.338 & $-3.67(0.035)$ & 2.273 \\
\hline$\beta_{1}$ & 0.502 & $11.28(0.000)$ & 0.045 \\
\hline$\beta_{2}$ & 0.235 & $4.63(0.000)$ & 0.051 \\
\hline$\beta_{3}$ & 1.090 & $3.24(0.048)$ & 0.337 \\
\hline & & & \\
\hline
\end{tabular}

Table 8: Parameter Estimates for the Univariate Regime Switching Model in Detail

\begin{tabular}{|c|c|c|c|c|}
\hline Strategy & 1-Emerging Markets & 2-Fund Weighted & 3-Funds of Funds & 4-Macro \\
\hline \hline State & & & & \\
\hline$S_{1}$ & $0.4052(0.000)$ & $0.5959(0.000)$ & $0.5028(0.000)$ & $0.4176(0.000)$ \\
\hline$S_{2}$ & $0.6803(0.000)$ & $0.6542(0.000)$ & $0.4178(0.000)$ & $0.2167(0.000)$ \\
\hline$S_{3}$ & $0.8486(0.073)$ & $0.999(0.000)$ & $0.8046(0.025)$ & $0.7031(0.048)$ \\
\hline
\end{tabular}

Table 9: Adjusted- $R^{2}$ Values ( $p$-values) for the Univariate Regime Switching Model 


\section{Multivariate with Economic Factors}

\begin{tabular}{|c|l|c|c|c|}
\hline \multicolumn{2}{|c|}{ Strategy } & \multicolumn{3}{c|}{ 1-Emerging Markets } \\
\hline \hline State & Variable & EsTIMATE & T-STAT (P-VALUE) & SE \\
\hline \multirow{5}{*}{$S_{1}$} & $\beta_{1}($ MSCI) & 0.588 & $8.19(0.000)$ & 0.072 \\
\cline { 2 - 5 } & $\gamma_{1,3}(\pi)$ & 0.773 & $3.49(0.001)$ & 0.222 \\
\cline { 2 - 5 } & $\gamma_{1,5}(\mathrm{I})$ & -0.717 & $-1.40(0.165)$ & 0.514 \\
\cline { 2 - 5 } & $\gamma_{1,6}(\mathrm{i})$ & -1.195 & $-9.14(0.000)$ & 0.131 \\
\hline \multirow{5}{*}{$S_{2}$} & $\beta_{2}(\mathrm{MSCI})$ & 0.668 & $10.78(0.000)$ & 0.062 \\
\cline { 2 - 5 } & $\gamma_{2,1}(\mathrm{dGNP})$ & 0.650 & $1.39(0.170)$ & 0.469 \\
\cline { 2 - 5 } & $\gamma_{2,2}(\mathrm{U})$ & 0.185 & $2.11(0.038)$ & 0.088 \\
\cline { 2 - 5 } & $\gamma_{2,4}(\mathrm{C})$ & 2.115 & $1.52(0.133)$ & 1.392 \\
\cline { 2 - 5 } & $\gamma_{2,6}(\mathrm{i})$ & -1.134 & $-8.06(0.000)$ & 0.141 \\
\hline \multirow{5}{*}{$S_{3}$} & $\beta_{3}(\mathrm{MSCI})$ & 0.628 & $18.66(0.034)$ & 0.034 \\
\cline { 2 - 5 } & $\gamma_{3,1}(\mathrm{dGNP})$ & -1.398 & $-3.44(0.180)$ & 0.407 \\
\cline { 2 - 5 } & $\gamma_{3,3}(\pi)$ & 0.409 & $3.30(0.187)$ & 0.124 \\
\cline { 2 - 5 } & $\gamma_{3,6}(\mathrm{i})$ & -1.341 & $-12.76(0.050)$ & 0.105 \\
\hline
\end{tabular}

Table 10: Emerging Markets: Parameter Estimates for the Multivariate Regime Switching Model with Economic Factors in Detail

\begin{tabular}{|c|l|c|c|c|}
\hline \multicolumn{2}{|c|}{ Strategy } & \multicolumn{3}{|c|}{ 2-Fund Weighted } \\
\hline \hline State & Variable & EsTIMATE & T-STAT (P-VALUE) & SE \\
\hline \multirow{5}{*}{$S_{1}$} & $\beta_{1}(\mathrm{MSCI})$ & 0.344 & $12.00(0.000)$ & 0.029 \\
\cline { 2 - 5 } & $\gamma_{1,2}(\mathrm{U})$ & 0.042 & $1.23(0.220)$ & 0.034 \\
\cline { 2 - 5 } & $\gamma_{1,3}(\pi)$ & 0.262 & $2.19(0.030)$ & 0.120 \\
\cline { 2 - 5 } & $\gamma_{1,5}(\mathrm{I})$ & -0.654 & $-3.13(0.002)$ & 0.209 \\
\cline { 2 - 5 } & $\gamma_{1,6}(\mathrm{i})$ & -0.928 & $-17.81(0.000)$ & 0.052 \\
\hline \multirow{5}{*}{$S_{2}$} & $\beta_{2}(\mathrm{MSCI})$ & 0.331 & $10.61(0.000)$ & 0.031 \\
\cline { 2 - 5 } & $\gamma_{2,1}(\mathrm{dGNP})$ & 0.408 & $1.73(0.089)$ & 0.236 \\
\cline { 2 - 5 } & $\gamma_{2,2}(\mathrm{U})$ & 0.072 & $1.64(0.106)$ & 0.044 \\
\cline { 2 - 5 } & $\gamma_{2,4}(\mathrm{C})$ & 0.867 & $1.24(0.220)$ & 0.701 \\
\cline { 2 - 5 } & $\gamma_{2,6}(\mathrm{i})$ & -0.921 & $-13.01(0.000)$ & 0.071 \\
\hline \multirow{5}{*}{$S_{3}$} & $\beta_{3}(\mathrm{MSCI})$ & 0.359 & $69.12(0.009)$ & 0.005 \\
\cline { 2 - 5 } & $\gamma_{3,1}(\mathrm{dGNP})$ & 0.375 & $7.04(0.090)$ & 0.053 \\
\cline { 2 - 5 } & $\gamma_{3,5}(\mathrm{I})$ & 0.273 & $6.80(0.093)$ & 0.040 \\
\cline { 2 - 5 } & $\gamma_{3,6}(\mathrm{i})$ & -1.326 & $-150.15(0.004)$ & 0.009 \\
\hline
\end{tabular}

Table 11: Fund Weighted: Parameter Estimates for the Multivariate Regime Switching Model with Economic Factors in Detail 


\begin{tabular}{|c|l|c|c|c|}
\hline \multicolumn{2}{|c|}{ Strategy } & \multicolumn{3}{c|}{ 3-Funds of Funds } \\
\hline \hline State & Variable & ESTIMATE & T-STAT (P-VALUE) & SE \\
\hline \multirow{5}{*}{$S_{1}$} & $\beta_{1}$ (MSCI) & 0.252 & $8.57(0.000)$ & 0.029 \\
\cline { 2 - 5 } & $\gamma_{1,2}(\mathrm{U})$ & 0.052 & $2.04(0.043)$ & 0.025 \\
\cline { 2 - 5 } & $\gamma_{1,5}$ (I) & -0.304 & $-1.82(0.071)$ & 0.167 \\
\cline { 2 - 5 } & $\gamma_{1,6}$ (i) & -0.869 & $-25.63(0.000)$ & 0.034 \\
\hline \multirow{5}{*}{$S_{2}$} & $\beta_{2}$ (MSCI) & 0.180 & $5.68(0.000)$ & 0.032 \\
\cline { 2 - 5 } & $\gamma_{2,1}$ (dGNP) & 0.292 & $1.24(0.220)$ & 0.236 \\
\cline { 2 - 5 } & $\gamma_{2,4}$ (C) & 1.946 & $2.73(0.008)$ & 0.713 \\
\cline { 2 - 5 } & $\gamma_{2,6}$ (i) & -0.912 & $-14.83(0.000)$ & 0.061 \\
\hline \multirow{5}{*}{$S_{3}$} & $\beta_{3}$ (MSCI) & 0.357 & $7.33(0.086)$ & 0.049 \\
\cline { 2 - 5 } & $\gamma_{3,1}$ (dGNP) & -2.778 & $-5.56(0.113)$ & 0.500 \\
\cline { 2 - 5 } & $\gamma_{3,5}$ (I) & 1.283 & $3.40(0.182)$ & 0.977 \\
\cline { 2 - 5 } & $\gamma_{3,6}$ (i) & -1.216 & $-14.68(0.043)$ & 0.084 \\
\hline
\end{tabular}

Table 12: Funds of Funds: Parameter Estimates for the Multivariate Regime Switching Model with Economic Factors in Detail

\begin{tabular}{|c|l|c|c|c|}
\hline \multicolumn{2}{|c|}{ Strategy } & \multicolumn{3}{c|}{ 4-Macro } \\
\hline \hline State & Variable & ESTIMATE & T-STAT (P-VALUE) & SE \\
\hline \multirow{5}{*}{$S_{1}$} & $\beta_{1}(\mathrm{MSCI})$ & 0.389 & $8.00(0.000)$ & 0.049 \\
\cline { 2 - 5 } & $\gamma_{1,1}(\mathrm{dGNP})$ & -0.225 & $-0.91(0.364)$ & 0.247 \\
\cline { 2 - 5 } & $\gamma_{1,3}(\pi)$ & 0.496 & $3.25(0.001)$ & 0.153 \\
\cline { 2 - 5 } & $\gamma_{1,5}(\mathrm{I})$ & -1.101 & $-3.16(0.002)$ & 0.348 \\
\cline { 2 - 5 } & $\gamma_{1,6}(\mathrm{i})$ & -0.971 & $-10.74(0.000)$ & 0.090 \\
\hline \multirow{5}{*}{$S_{2}$} & $\beta_{2}(\mathrm{MSCI})$ & 0.073 & $1.90(0.062)$ & 0.038 \\
\cline { 2 - 5 } & $\gamma_{2,1}(\mathrm{dGNP})$ & 0.436 & $1.50(0.138)$ & 0.290 \\
\cline { 2 - 5 } & $\gamma_{2,2}(\mathrm{U})$ & 0.104 & $1.93(0.057)$ & 0.054 \\
\cline { 2 - 5 } & $\gamma_{2,6}(\mathrm{i})$ & -0.946 & $-11.65(0.000)$ & 0.081 \\
\hline \multirow{5}{*}{$S_{3}$} & $\beta_{3}$ (MSCI) & 0.374 & $8.19(0.077)$ & 0.046 \\
\cline { 2 - 5 } & $\gamma_{3,1}$ (dGNP) & -2.973 & $-6.33(0.100)$ & 0.470 \\
\cline { 2 - 5 } & $\gamma_{3,5}$ (I) & 2.095 & $5.92(0.107)$ & 0.354 \\
\cline { 2 - 5 } & $\gamma_{3,6}$ (i) & -1.166 & $-14.98(0.042)$ & 0.078 \\
\hline
\end{tabular}

Table 13: Macro: Parameter Estimates for the Multivariate Regime Switching Model with Economic Factors in Detail

\begin{tabular}{|c|c|c|c|c|}
\hline Strategy & 1-Emerging Markets & 2-Fund Weighted & 3-Funds of Funds & 4-Macro \\
\hline \hline State & & & & \\
\hline$S_{1}$ & $0.5685(0.000)$ & $0.8836(0.000)$ & $0.8954(0.000)$ & $0.7196(0.000)$ \\
\hline$S_{2}$ & $0.7969(0.000)$ & $0.8894(0.000)$ & $0.8587(0.000)$ & $0.7863(0.000)$ \\
\hline$S_{3}$ & $0.9883(0.073)$ & $0.9998(0.009)$ & $0.9845(0.083)$ & $0.984(0.085)$ \\
\hline
\end{tabular}

Table 14: Adjusted- $R^{2}$ Values ( $p$-values) for the Multivariate Regime Switching Model with Economic Factors 


\section{Quadratic with Economic Factors}

\begin{tabular}{|c|l|c|c|c|}
\hline \multicolumn{2}{|l|}{ Strategy } & \multicolumn{3}{|c|}{ 1-Emerging Markets } \\
\hline \hline State & Variable & ESTIMATE & T-STAT (P-VALUE) & SE \\
\hline \multirow{5}{*}{$S_{1}$} & $\beta_{1,1}(\mathrm{MSCI})$ & 0.550 & $7.17(0.000)$ & 0.077 \\
\cline { 2 - 5 } & $\beta_{1,2}\left(\mathrm{MSCI}^{2}\right)$ & 0.025 & $1.40(0.163)$ & 0.018 \\
\cline { 2 - 5 } & $\gamma_{1,1,1}(\mathrm{dGNP})$ & -0.730 & $-1.72(0.087)$ & 0.424 \\
\cline { 2 - 5 } & $\gamma_{1,3,2}\left(\pi^{2}\right)$ & 0.110 & $2.75(0.007)$ & 0.040 \\
\cline { 2 - 5 } & $\gamma_{1,5,2}\left(\mathrm{I}^{2}\right)$ & -1.118 & $-2.38(0.019)$ & 0.470 \\
\cline { 2 - 5 } & $\gamma_{1,6,1}(\mathrm{i})$ & 0.749 & $1.93(0.056)$ & 0.389 \\
\cline { 2 - 5 } & $\gamma_{1,6,2}\left(\mathrm{i}^{2}\right)$ & -0.310 & $-4.78(0.000)$ & 0.065 \\
\hline \multirow{5}{*}{$S_{2}$} & $\beta_{2,1}\left(\mathrm{MSCI}^{2}\right)$ & 0.580 & $8.31(0.000)$ & 0.070 \\
\cline { 2 - 5 } & $\beta_{2,2}\left(\mathrm{MSCI}^{2}\right)$ & -0.021 & $-2.55(0.013)$ & 0.008 \\
\cline { 2 - 5 } & $\left.\gamma_{2,1,2}(\mathrm{dGNP})^{2}\right)$ & 0.807 & $3.04(0.003)$ & 0.265 \\
\cline { 2 - 5 } & $\gamma_{2,3,1}(\pi)$ & 1.688 & $2.12(0.038)$ & 0.798 \\
\cline { 2 - 5 } & $\gamma_{2,3,2}\left(\pi^{2}\right)$ & -0.303 & $-2.04(0.046)$ & 0.149 \\
\cline { 2 - 5 } & $\gamma_{2,4,1}(\mathrm{C})$ & 4.154 & $2.69(0.009)$ & 1.544 \\
\cline { 2 - 5 } & $\gamma_{2,5,2}\left(\mathrm{I}^{2}\right)$ & 1.277 & $2.06(0.044)$ & 0.621 \\
\cline { 2 - 5 } & $\gamma_{2,6,1}(\mathrm{i})$ & -2.029 & $-3.03(0.003)$ & 0.669 \\
\cline { 2 - 5 } & $\gamma_{2,6,2}\left(\mathrm{i}^{2}\right)$ & 0.102 & $1.36(0.180)$ & 0.075 \\
\hline \multirow{5}{*}{$S_{3}$} & $\beta_{3,2}\left(\mathrm{MSCI}^{2}\right)$ & 0.069 & $75.85(0.008)$ & 0.001 \\
\cline { 2 - 5 } & $\gamma_{3,1,2}\left(\mathrm{dGNP}^{2}\right)$ & -3.203 & $-36.93(0.017)$ & 0.087 \\
\cline { 2 - 5 } & $\gamma_{3,5,1}(\mathrm{I})$ & 0.310 & $4.48(0.140)$ & 0.069 \\
\cline { 2 - 5 } & $\gamma_{3,6,2}\left(\mathrm{i}^{2}\right)$ & -0.128 & $-64.28(0.010)$ & 0.002 \\
\hline
\end{tabular}

Table 15: Emerging Markets: Parameter Estimates for the Quadratic Regime Switching Model with Economic Factors in Detail 


\begin{tabular}{|c|l|c|c|c|}
\hline \multicolumn{2}{|l|}{ Strategy } & \multicolumn{3}{|c|}{ 2-Fund Weighted } \\
\hline \hline State & Variable & EsTIMATE & T-STAT (P-VALUE) & SE \\
\hline \multirow{5}{*}{} & $\beta_{1,1}(\mathrm{MSCI})$ & 0.318 & $10.22(0.000)$ & 0.031 \\
\cline { 2 - 5 } & $\beta_{1,2}\left(\mathrm{MSCI}^{2}\right)$ & 0.008 & $1.09(0.278)$ & 0.007 \\
\cline { 2 - 5 } & $\gamma_{1,1,1}(\mathrm{dGNP})$ & -1.160 & $-2.93(0.004)$ & 0.396 \\
\cline { 2 - 5 } & $\left.\gamma_{1,1,2}(\mathrm{dGNP})^{2}\right)$ & 0.470 & $1.868(0.064)$ & 0.251 \\
\cline { 2 - 5 } & $\gamma_{1,2,1}(\mathrm{U})$ & 0.376 & $1.56(0.122)$ & 0.242 \\
\cline { 2 - 5 } & $\gamma_{1,2,2}\left(\mathrm{U}^{2}\right)$ & -0.027 & $-1.09(0.279)$ & 0.025 \\
\cline { 2 - 5 } & $\gamma_{1,4,2}\left(\mathrm{C}^{2}\right)$ & 1.313 & $1.43(0.155)$ & 0.919 \\
\cline { 2 - 5 } & $\gamma_{1,5,1}(\mathrm{I})$ & -0.346 & $-1.34(0.183)$ & 0.258 \\
\cline { 2 - 5 } & $\gamma_{1,5,2}\left(\mathrm{I}^{2}\right)$ & -0.522 & $-2.02(0.454)$ & 0.259 \\
\cline { 2 - 5 } & $\gamma_{1,6,1}(\mathrm{i})$ & -0.613 & $-2.57(0.011)$ & 0.239 \\
\cline { 2 - 5 } & $\gamma_{1,6,2}\left(\mathrm{i}^{2}\right)$ & -0.054 & $-1.71(0.089)$ & 0.032 \\
\hline \multirow{5}{*}{$S_{2}$} & $\beta_{2,1}(\mathrm{MSCI})$ & 0.295 & $9.10(0.000)$ & 0.032 \\
\cline { 2 - 5 } & $\beta_{2,2}\left(\mathrm{MSCI}{ }^{2}\right)$ & -0.006 & $-1.64(0.105)$ & 0.004 \\
\cline { 2 - 5 } & $\gamma_{2,1,1}(\mathrm{dGNP})$ & 0.346 & $1.55(0.126)$ & 0.223 \\
\cline { 2 - 5 } & $\gamma_{2,1,2}(\mathrm{dGNP})$ & 0.536 & $4.36(0.000)$ & 0.123 \\
\cline { 2 - 5 } & $\gamma_{2,4,1}(\mathrm{C})$ & 1.305 & $2.07(0.043)$ & 0.631 \\
\cline { 2 - 5 } & $\gamma_{2,5,2}\left(\mathrm{I}^{2}\right)$ & 0.287 & $1.07(0.288)$ & 0.268 \\
\cline { 2 - 5 } & $\gamma_{2,6,1}(\mathrm{i})$ & -0.941 & $-15.32(0.000)$ & 0.061 \\
\hline \multirow{5}{*}{$S_{3}$} & $\beta_{3,1}(\mathrm{MSCI})$ & 0.359 & $69.12(0.009)$ & 0.005 \\
\cline { 2 - 5 } & $\gamma_{3,1,1}(\mathrm{dGNP})$ & 0.375 & $7.04(0.090)$ & 0.053 \\
\cline { 2 - 5 } & $\gamma_{3,5,1}(\mathrm{I})$ & 0.273 & $6.80(0.093)$ & 0.040 \\
\cline { 2 - 5 } & $\gamma_{3,6,1}(\mathrm{i})$ & -1.326 & $-150.15(0.004)$ & 0.009 \\
\hline
\end{tabular}

Table 16: Fund Weighted: Parameter Estimates for the Quadratic Regime Switching Model with Economic Factors in Detail

\begin{tabular}{|c|l|c|c|c|}
\hline \multicolumn{2}{|c|}{ Strategy } & \multicolumn{3}{c|}{ 3-Funds of Funds } \\
\hline \hline State & Variable & EsTIMATE & T-STAT (P-VALUE) & SE \\
\hline \multirow{5}{*}{$S_{1}$} & $\beta_{1,1}(\mathrm{MSCI})$ & 0.254 & $8.83(0.000)$ & 0.029 \\
\cline { 2 - 5 } & $\gamma_{1,4,2}\left(\mathrm{C}^{2}\right)$ & 1.103 & $1.21(0.229)$ & 0.914 \\
\cline { 2 - 5 } & $\gamma_{1,5,1}(\mathrm{I})$ & -0.486 & $-2.67(0.008)$ & 0.182 \\
\cline { 2 - 5 } & $\gamma_{1,6,1}(\mathrm{i})$ & -0.505 & $-4.13(0.000)$ & 0.122 \\
\cline { 2 - 5 } & $\gamma_{1,6,2}\left(\mathrm{i}^{2}\right)$ & -0.060 & $-2.70(0.008)$ & 0.022 \\
\hline \multirow{5}{*}{$S_{2}$} & $\beta_{2,1}\left(\mathrm{MSCI}^{2}\right.$ & 0.140 & $4.17(0.000)$ & 0.034 \\
\cline { 2 - 5 } & $\beta_{2,2}\left(\mathrm{MSCI}^{2}\right)$ & -0.007 & $-1.96(0.055)$ & 0.004 \\
\cline { 2 - 5 } & $\gamma_{2,1,1}(\mathrm{dGNP})$ & 0.243 & $1.04(0.303)$ & 0.234 \\
\cline { 2 - 5 } & $\gamma_{2,1,2}(\mathrm{dGNP})$ & 0.395 & $2.98(0.004)$ & 0.133 \\
\cline { 2 - 5 } & $\gamma_{2,4,1}(\mathrm{C})$ & 2.070 & $3.07(0.003)$ & 0.674 \\
\cline { 2 - 5 } & $\gamma_{2,6,1}(\mathrm{i})$ & -1.202 & $-6.67(0.000)$ & 0.180 \\
\cline { 2 - 5 } & $\gamma_{2,6,2}\left(\mathrm{i}^{2}\right)$ & 0.039 & $1.68(0.098)$ & 0.023 \\
\hline \multirow{5}{*}{$S_{3}$} & $\beta_{3,1}(\mathrm{MSCI})$ & 1.128 & $8.98(0.071)$ & 0.126 \\
\cline { 2 - 5 } & $\gamma_{3,2,1}(\mathrm{U})$ & -0.769 & $-6.74(0.094)$ & 0.114 \\
\cline { 2 - 5 } & $\gamma_{3,6,1}(\mathrm{i})$ & -4.435 & $-16.34(0.039)$ & 0.272 \\
\cline { 2 - 5 } & $\gamma_{3,6,2}\left(\mathrm{i}^{2}\right)$ & 0.373 & $13.71(0.046)$ & 0.027 \\
\hline
\end{tabular}

Table 17: Funds of Funds: Parameter Estimates for the Quadratic Regime Switching Model with Economic Factors in Detail 


\begin{tabular}{|c|l|c|c|c|}
\hline \multicolumn{2}{|c|}{ Strategy } & \multicolumn{3}{|c|}{ 4-Macro } \\
\hline \hline State & Variable & EsT IMATE & T-STAT (P-VALUE) & SE \\
\hline \multirow{5}{*}{$S_{1}$} & $\beta_{1,1}(\mathrm{MSCI})$ & 0.358 & $6.72(0.000)$ & 0.053 \\
\cline { 2 - 5 } & $\beta_{1,2}\left(\mathrm{MSCI}^{2}\right)$ & 0.021 & $1.71(0.090)$ & 0.012 \\
\cline { 2 - 5 } & $\gamma_{1,1,2}\left(\mathrm{dGNP}^{2}\right)$ & -0.453 & $-2.52(0.013)$ & 0.179 \\
\cline { 2 - 5 } & $\gamma_{1,3,1}(\pi)$ & 0.076 & $2.58(0.011)$ & 0.029 \\
\cline { 2 - 5 } & $\gamma_{1,5,1}(\mathrm{I})$ & -0.627 & $-1.44(0.151)$ & 0.434 \\
\cline { 2 - 5 } & $\gamma_{1,5,2}\left(\mathrm{I}^{2}\right)$ & -0.836 & $-2.07(0.040)$ & 0.403 \\
\cline { 2 - 5 } & $\gamma_{1,6,2}\left(\mathrm{i}^{2}\right)$ & -0.153 & $-12.21(0.000)$ & 0.013 \\
\hline \multirow{5}{*}{$S_{2}$} & $\beta_{2,1}(\mathrm{MSCI})$ & 0.082 & $2.10(0.039)$ & 0.039 \\
\cline { 2 - 5 } & $\gamma_{2,1,1}(\mathrm{dGNP})$ & 0.357 & $1.30(0.199)$ & 0.276 \\
\cline { 2 - 5 } & $\gamma_{2,1,2}(\mathrm{dGNP})$ & 0.404 & $2.57(0.012)$ & 0.157 \\
\cline { 2 - 5 } & $\gamma_{2,3,1}(\pi)$ & 0.260 & $1.60(0.114)$ & 0.162 \\
\cline { 2 - 5 } & $\gamma_{2,6,1}(\mathrm{i})$ & -1.077 & $-8.73(0.000)$ & 0.123 \\
\hline \multirow{5}{*}{$S_{3}$} & $\beta_{3,1}(\mathrm{MSCI})$ & 0.115 & $14.27(0.045)$ & 0.008 \\
\cline { 2 - 5 } & $\gamma_{3,1,1}(\mathrm{dGNP})$ & 3.265 & $17.03(0.037)$ & 0.192 \\
\cline { 2 - 5 } & $\gamma_{3,4,2}\left(\mathrm{C}^{2}\right)$ & 51.251 & $30.69(0.021)$ & 1.670 \\
\cline { 2 - 5 } & $\gamma_{3,6,2}\left(\mathrm{i}^{2}\right)$ & -2.712 & $-45.63(0.014)$ & 0.059 \\
\hline
\end{tabular}

Table 18: Macro: Parameter Estimates for the Quadratic Regime Switching Model with Economic Factors in Detail

\begin{tabular}{|c|c|c|c|c|}
\hline Strategy & 1-Emerging Markets & 2-Fund Weighted & 3-Funds of Funds & 4-Macro \\
\hline \hline State & & & & \\
\hline$S_{1}$ & $0.606(0.000)$ & $0.8869(0.000)$ & $0.898(0.000)$ & $0.7309(0.000)$ \\
\hline$S_{2}$ & $0.8205(0.000)$ & $0.9104(0.000)$ & $0.8762(0.000)$ & $0.797(0.000)$ \\
\hline$S_{3}$ & $0.9994(0.017)$ & $0.9998(0.009)$ & $0.9986(0.025)$ & $0.9994(0.017)$ \\
\hline
\end{tabular}

Table 19: Adjusted- $R^{2}$ Values ( $p$-values) for the Multivariate Quadratic Regime Switching Model with Economic Factors 


\section{Multivariate with Financial Factors}

\begin{tabular}{|c|l|c|c|c|}
\hline \multicolumn{2}{|c|}{ Strategy } & \multicolumn{3}{|c|}{ 1-Emerging Markets } \\
\hline \hline State & Variable & EstimATE & T-STAT (P-VALUE) & SE \\
\hline \multirow{5}{*}{$S_{1}$} & $\beta_{1}(\mathrm{MSCI})$ & 0.573 & $7.45(0.000)$ & 0.077 \\
\cline { 2 - 5 } & $\delta_{1,2}(\mathrm{Gold})$ & 0.093 & $1.65(0.101)$ & 0.057 \\
\cline { 2 - 5 } & $\delta_{1,3}(\mathrm{TS})$ & 1.081 & $5.78(0.000)$ & 0.187 \\
\cline { 2 - 5 } & $\delta_{1,4}(\mathrm{CS})$ & 2.889 & $2.28(0.024)$ & 1.267 \\
\cline { 2 - 5 } & $\delta_{1,5}(\mathrm{LS})$ & 0.199 & $2.21(0.028)$ & 0.090 \\
\cline { 2 - 5 } & $\delta_{1,9}(\mathrm{BGC})$ & 0.650 & $2.02(0.045)$ & 0.321 \\
\cline { 2 - 5 } & $\delta_{1,10}(\mathrm{BGB})$ & -0.709 & $-2.22(0.028)$ & 0.320 \\
\hline \multirow{5}{*}{$S_{2}$} & $\beta_{2}(\mathrm{MSCI})$ & 0.594 & $6.55(0.000)$ & 0.091 \\
\cline { 2 - 5 } & $\delta_{2,2}(\mathrm{Gold})$ & 0.118 & $1.52(0.133)$ & 0.078 \\
\cline { 2 - 5 } & $\delta_{2,3}(\mathrm{TS})$ & 1.612 & $5.90(0.000)$ & 0.273 \\
\cline { 2 - 5 } & $\delta_{2,4}(\mathrm{CS})$ & 1.950 & $3.33(0.001)$ & 0.586 \\
\cline { 2 - 5 } & $\delta_{2,5}(\mathrm{LS})$ & 0.279 & $2.97(0.004)$ & 0.094 \\
\cline { 2 - 5 } & $\delta_{2,7}(\mathrm{dVIX})$ & -0.031 & $-1.33(0.189)$ & 0.023 \\
\cline { 2 - 5 } & $\delta_{2,8}(\mathrm{MOM})$ & 0.056 & $1.14(0.260)$ & 0.049 \\
\cline { 2 - 5 } & $\delta_{2,9}(\mathrm{BGC})$ & -0.063 & $-8.09(0.000)$ & 0.008 \\
\hline \multirow{5}{*}{$S_{3}$} & $\beta_{3}(\mathrm{MSCI})$ & -0.479 & $-1196.6(0.001)$ & 0.000 \\
\cline { 2 - 5 } & $\delta_{3,1}(\mathrm{SP})$ & 0.507 & $835.0(0.001)$ & 0.001 \\
\cline { 2 - 5 } & $\delta_{3,3}(\mathrm{TS})$ & 2.146 & $1879.1(0.000)$ & 0.001 \\
\cline { 2 - 5 } & $\delta_{3,8}(\mathrm{MOM})$ & 0.131 & $351.1(0.002)$ & 0.000 \\
\hline
\end{tabular}

Table 20: Emerging Markets: Parameter Estimates for the Multivariate Regime Switching Model with Financial Factors in Detail 


\begin{tabular}{|c|c|c|c|c|}
\hline \multicolumn{2}{|c|}{ Strategy } & \multicolumn{3}{|c|}{ 2-Fund Weighted } \\
\hline State & Variable & ESTIMATE & T-STAT (P-VALUE) & $\mathrm{SE}$ \\
\hline \multirow{9}{*}{$S_{1}$} & $\beta_{1}(\mathrm{MSCI})$ & 0.243 & $4.51(0.000)$ & 0.054 \\
\hline & $\delta_{1,1}(\mathrm{SP})$ & 0.117 & $2.17(0.032)$ & 0.054 \\
\hline & $\delta_{1,2}($ Gold $)$ & 0.058 & $2.47(0.014)$ & 0.023 \\
\hline & $\delta_{1,3}(\mathrm{TS})$ & 0.780 & $10.31(0.000)$ & 0.076 \\
\hline & $\delta_{1,4}(\mathrm{CS})$ & 1.864 & $3.50(0.001)$ & 0.533 \\
\hline & $\delta_{1,5}(\mathrm{LS})$ & 0.232 & $6.31(0.000)$ & 0.037 \\
\hline & $\delta_{1,8}(\mathrm{MOM})$ & 0.071 & $2.25(0.026)$ & 0.032 \\
\hline & $\delta_{1,9}(\mathrm{BGC})$ & 0.796 & $6.12(0.000)$ & 0.130 \\
\hline & $\delta_{1,10}(\mathrm{BGB})$ & -0.845 & $-6.52(0.000)$ & 0.130 \\
\hline \multirow{8}{*}{$S_{2}$} & $\beta_{2}(\mathrm{MSCI})$ & 0.247 & $5.02(0.000)$ & 0.050 \\
\hline & $\delta_{2,2}($ Gold $)$ & 0.078 & $1.76(0.084)$ & 0.044 \\
\hline & $\delta_{2,3}(\mathrm{TS})$ & 1.110 & $7.05(0.000)$ & 0.157 \\
\hline & $\delta_{2,4}(\mathrm{CS})$ & 1.539 & $4.76(0.000)$ & 0.324 \\
\hline & $\delta_{2,5}(\mathrm{LS})$ & 0.195 & $3.63(0.001)$ & 0.054 \\
\hline & $\overline{\delta_{2,6}(\mathrm{VG})}$ & -0.110 & $-2.39(0.020)$ & 0.046 \\
\hline & $\delta_{2,7}(\mathrm{dVIX})$ & -0.018 & $-1.36(0.178)$ & 0.013 \\
\hline & $\delta_{2,9}(\mathrm{BGC})$ & -0.055 & $-12.44(0.000)$ & 0.004 \\
\hline \multirow{4}{*}{$S_{3}$} & $\beta_{3}(\mathrm{MSCI})$ & -0.055 & $-30.09(0.021)$ & 0.002 \\
\hline & $\delta_{3,2}($ Gold $)$ & 0.268 & $54.47(0.012)$ & 0.005 \\
\hline & $\delta_{3,3}(\mathrm{TS})$ & -0.314 & $-25.66(0.025)$ & 0.012 \\
\hline & $\delta_{3,5}(\mathrm{LS})$ & 1.385 & $261.91(0.002)$ & 0.005 \\
\hline
\end{tabular}

Table 21: Fund Weighted: Parameter Estimates for the Multivariate Regime Switching Model with Financial Factors in Detail 


\begin{tabular}{|c|c|c|c|c|}
\hline \multicolumn{2}{|c|}{ Strategy } & \multicolumn{3}{|c|}{ 3-Funds of Funds } \\
\hline State & Variable & ESTIMATE & T-STAT (P-VALUE) & $\mathrm{SE}$ \\
\hline \multirow{8}{*}{$S_{1}$} & $\beta_{1}(\mathrm{MSCI})$ & 0.252 & $6.80(0.000)$ & 0.037 \\
\hline & $\delta_{1,2}($ Gold $)$ & 0.071 & $2.59(0.010)$ & 0.027 \\
\hline & $\delta_{1,3}(\mathrm{TS})$ & 0.712 & $7.95(0.000)$ & 0.090 \\
\hline & $\delta_{1,4}(\mathrm{CS})$ & 1.656 & $2.69(0.009)$ & 0.623 \\
\hline & $\delta_{1,5}(\mathrm{LS})$ & 0.086 & $1.98(0.050)$ & 0.043 \\
\hline & $\delta_{1,8}(\mathrm{MOM})$ & 0.094 & $2.53(0.012)$ & 0.037 \\
\hline & $\delta_{1,9}(\mathrm{BGC})$ & 1.080 & $7.02(0.000)$ & 0.154 \\
\hline & $\delta_{1,10}(\mathrm{BGB})$ & -1.129 & $-7.37(0.000)$ & 0.153 \\
\hline \multirow{9}{*}{$S_{2}$} & $\beta_{2}(\mathrm{MSCI})$ & 0.121 & $2.58(0.012)$ & 0.047 \\
\hline & $\delta_{2,2}$ (Gold) & 1.080 & $2.02(0.048)$ & 0.040 \\
\hline & $\delta_{2,3}(\mathrm{TS})$ & 1.185 & $8.51(0.000)$ & 0.139 \\
\hline & $\delta_{2,4}(\mathrm{CS})$ & 1.485 & $4.80(0.000)$ & 0.309 \\
\hline & $\delta_{2,5}(\mathrm{LS})$ & 0.122 & $2.54(0.013)$ & 0.048 \\
\hline & $\delta_{2,6}(\mathrm{VG})$ & -0.087 & $-2.11(0.039)$ & 0.041 \\
\hline & $\delta_{2,7}(\mathrm{dVIX})$ & -0.021 & $-1.74(0.086)$ & 0.012 \\
\hline & $\delta_{2,8}(\mathrm{MOM})$ & 0.044 & $-1.74(0.087)$ & 0.025 \\
\hline & $\delta_{2,10}(\mathrm{BGB})$ & -0.056 & $-14.03(0.000)$ & 0.004 \\
\hline \multirow{4}{*}{$S_{3}$} & $\beta_{3}(\mathrm{MSCI})$ & 2.245 & $16.36(0.032)$ & 0.137 \\
\hline & $\delta_{3,3}(\mathrm{TS})$ & 1.288 & $25.09(0.019)$ & 0.051 \\
\hline & $\delta_{3,5}(\mathrm{LS})$ & 1.197 & $33.27(0.025)$ & 0.036 \\
\hline & $\delta_{3,10}(\mathrm{BGB})$ & -0.219 & $-19.66(0.039)$ & 0.011 \\
\hline
\end{tabular}

Table 22: Funds of Funds: Parameter Estimates for the Multivariate Regime Switching Model with Financial Factors in Detail 


\begin{tabular}{|c|l|c|c|c|}
\hline \multicolumn{2}{|l}{ Strategy } & \multicolumn{3}{|c|}{ 4-Macro } \\
\hline \hline State & Variable & EsTIMATE & T-STAT (P-VALUE) & SE \\
\hline \multirow{5}{*}{} & $\beta_{1}(\mathrm{MSCI})$ & 0.266 & $3.01(0.003)$ & 0.088 \\
\cline { 2 - 5 } & $\delta_{1,1}(\mathrm{SP})$ & 0.158 & $1.76(0.081)$ & 0.090 \\
\cline { 2 - 5 } & $\delta_{1,2}(\mathrm{Gold})$ & 0.150 & $3.91(0.000)$ & 0.038 \\
\cline { 2 - 5 }$\delta_{1,3}(\mathrm{TS})$ & 0.967 & $7.77(0.000)$ & 0.124 \\
\cline { 2 - 5 } & $\delta_{1,4}(\mathrm{CS})$ & 1.050 & $1.20(0.233)$ & 0.877 \\
\cline { 2 - 5 } & $\delta_{1,5}(\mathrm{LS})$ & 0.088 & $1.46(0.147)$ & 0.060 \\
\cline { 2 - 5 } & $\delta_{1,6}(\mathrm{VG})$ & 0.087 & $1.15(0.253)$ & 0.076 \\
\cline { 2 - 5 } & $\delta_{1,8}(\mathrm{MOM})$ & 0.110 & $2.03(0.044)$ & 0.054 \\
\cline { 2 - 5 } & $\delta_{1,9}(\mathrm{BGC})$ & 0.464 & $2.15(0.033)$ & 0.216 \\
\cline { 2 - 5 } & $\delta_{1,10}(\mathrm{BGB})$ & -0.512 & $-2.38(0.018)$ & 0.215 \\
\hline \multirow{5}{*}{$S_{2}$} & $\beta_{2}(\mathrm{MSCI})$ & 0.100 & $1.93(0.057)$ & 0.052 \\
\cline { 2 - 5 } & $\delta_{2,2}(\mathrm{Gold})$ & 0.106 & $1.79(0.079)$ & 0.060 \\
\cline { 2 - 5 } & $\delta_{2,3}(\mathrm{TS})$ & 1.060 & $5.01(0.000)$ & 0.212 \\
\cline { 2 - 5 } & $\delta_{2,4}(\mathrm{CS})$ & 2.124 & $4.74(0.000)$ & 0.448 \\
\cline { 2 - 5 } & $\delta_{2,5}(\mathrm{LS})$ & 0.138 & $1.94(0.056)$ & 0.071 \\
\cline { 2 - 5 } & $\delta_{2,8}(\mathrm{MOM})$ & 0.067 & $1.76(0.084)$ & 0.038 \\
\cline { 2 - 5 } & $\delta_{2,9}(\mathrm{BGC})$ & -0.061 & $-10.19(0.000)$ & 0.006 \\
\hline \multirow{5}{*}{$S_{3}$} & $\beta_{3}(\mathrm{MSCI})$ & -31.02 & $-7017(0.000)$ & 0.004 \\
\cline { 2 - 5 } & $\delta_{3,6}(\mathrm{VG})$ & 2.279 & $3310(0.000)$ & 0.001 \\
\cline { 2 - 5 } & $\delta_{3,8}(\mathrm{MOM})$ & 2.645 & $6368(0.000)$ & 0.000 \\
\cline { 2 - 5 } & $\delta_{3,9}(\mathrm{BGC})$ & 2.635 & $6934(0.000)$ & 0.000 \\
\hline
\end{tabular}

Table 23: Macro: Parameter Estimates for the Multivariate Regime Switching Model with Financial Factors in Detail

\begin{tabular}{|c|c|c|c|c|}
\hline Strategy & 1-Emerging Markets & 2-Fund Weighted & 3-Funds of Funds & 4-Macro \\
\hline \hline State & & & & \\
\hline$S_{1}$ & $0.5451(0.000)$ & $0.8687(0.000)$ & $0.8444(0.000)$ & $0.7177(0.000)$ \\
\hline$S_{2}$ & $0.8152(0.000)$ & $0.8676(0.000)$ & $0.8751(0.000)$ & $0.6984(0.000)$ \\
\hline$S_{3}$ & $1(0.001)$ & $1(0.002)$ & $0.9994(0.017)$ & $1(0.000)$ \\
\hline
\end{tabular}

Table 24: Adjusted- $R^{2}$ Values ( $p$-values) for the Multivariate Regime Switching Model with Financial Factors 


\section{Quadratic with Financial Factors}

\begin{tabular}{|c|c|c|c|c|}
\hline \multicolumn{2}{|r|}{ Strategy } & \multicolumn{3}{|c|}{ 1-Emerging Markets } \\
\hline$\overline{\text { State }}$ & "Variable & $\overline{\overline{\text { ESTIMATE }}}$ & 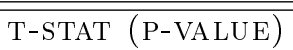 & $\mathrm{SE}$ \\
\hline \multirow{9}{*}{$S_{1}$} & $\beta_{1,1}(\mathrm{MSCI})$ & 0.584 & $7.53(0.000)$ & 0.077 \\
\hline & $\delta_{1,2,1}$ (Gold) & 0.081 & $1.45(0.149)$ & 0.056 \\
\hline & $\delta_{1,2,2}\left(\mathrm{Gold}^{2}\right)$ & 0.723 & $2.16(0.032)$ & 0.335 \\
\hline & $\delta_{1,3,1}(\mathrm{TS})$ & 1.145 & $6.21(0.000)$ & 0.184 \\
\hline & $\delta_{1,3,2}\left(\mathrm{TS}^{2}\right)$ & -0.853 & $-2.60(0.010)$ & 0.328 \\
\hline & $\delta_{1,4,1}(\mathrm{CS})$ & 19.986 & $2.35(0.020)$ & 2.497 \\
\hline & $\delta_{1,5,1}(\mathrm{LS})$ & 0.190 & $2.15(0.033)$ & 0.088 \\
\hline & $\delta_{1,8,2}\left(\mathrm{MOM}^{2}\right)$ & -9.743 & $-2.04(0.043)$ & 4.783 \\
\hline & $\delta_{1,10,2}\left(\mathrm{BGB}^{2}\right)$ & 0.047 & $2.10(0.037)$ & 0.022 \\
\hline \multirow{10}{*}{$S_{2}$} & $\beta_{2,1}(\mathrm{MSCI})$ & 0.597 & $8.97(0.000)$ & 0.067 \\
\hline & $\delta_{2,2,1}($ Gold $)$ & 0.102 & $1.33(0.189)$ & 0.077 \\
\hline & $\delta_{2,2,2}\left(\operatorname{Gold}^{2}\right)$ & -0.067 & $-7.77(0.000)$ & 0.009 \\
\hline & $\delta_{2,3,1}(\mathrm{TS})$ & 1.838 & $6.07(0.000)$ & 0.303 \\
\hline & $\delta_{2,4,1}(\mathrm{CS})$ & 1.973 & $2.98(0.004)$ & 0.661 \\
\hline & $\delta_{2,5,1}(\mathrm{LS})$ & 0.198 & $1.84(0.071)$ & 0.108 \\
\hline & $\delta_{2,5,2}\left(\mathrm{LS}^{2}\right)$ & -0.014 & $-1.50(0.138)$ & 0.009 \\
\hline & $\delta_{2,6,1}(\mathrm{VG})$ & -0.135 & $-1.63(0.107)$ & 0.083 \\
\hline & $\delta_{2,6,2}\left(\mathrm{VG}^{2}\right)$ & 0.012 & $1.03(0.306)$ & 0.011 \\
\hline & $\delta_{2,10,2}\left(\mathrm{BGB}^{2}\right)$ & 0.021 & $1.83(0.072)$ & 0.011 \\
\hline
\end{tabular}

Table 25: Emerging Markets: Parameter Estimates for the Quadratic Regime Switching Model with Financial Factors in Detail 


\begin{tabular}{|c|c|c|c|c|}
\hline \multicolumn{2}{|r|}{ Strategy } & \multicolumn{3}{|c|}{ 2-Fund Weighted } \\
\hline State & "Variable & ESTIMATE & 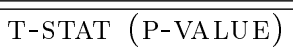 & $\mathrm{SE}$ \\
\hline \multirow{13}{*}{$S_{1}$} & $\beta_{1,1}(\mathrm{MSCI})$ & 0.199 & $3.58(0.000)$ & 0.056 \\
\hline & $\delta_{1,1,1}(\mathrm{SP})$ & 0.152 & $2.48(0.014)$ & 0.061 \\
\hline & $\delta_{1,1,2}\left(\mathrm{SP}^{2}\right)$ & 0.082 & $2.61(0.010)$ & 0.031 \\
\hline & $\delta_{1,2,1}($ Gold $)$ & 0.053 & $2.38(0.019)$ & 0.022 \\
\hline & $\delta_{1,2,2}\left(\mathrm{Gold}^{2}\right)$ & 0.927 & $6.97(0.000)$ & 0.133 \\
\hline & $\delta_{1,3,1}(\mathrm{TS})$ & 0.557 & $2.77(0.006)$ & 0.201 \\
\hline & $\delta_{1,3,2}\left(\mathrm{TS}^{2}\right)$ & -0.969 & $-7.31(0.000)$ & 0.133 \\
\hline & $\delta_{1,4,2}\left(\mathrm{CS}^{2}\right)$ & 0.014 & $1.31(0.192)$ & 0.011 \\
\hline & $\delta_{1,5,1}(\mathrm{LS})$ & 0.212 & $5.85(0.000)$ & 0.036 \\
\hline & $\delta_{1,5,2}\left(\mathrm{LS}^{2}\right)$ & -0.014 & $-1.31(0.192)$ & 0.010 \\
\hline & $\delta_{1,7,2}\left(\mathrm{dVIX}^{2}\right)$ & 0.090 & $1.24(0.219)$ & 0.073 \\
\hline & $\delta_{1,8,2}\left(\mathrm{MOM}^{2}\right)$ & 0.992 & $3.27(0.001)$ & 0.303 \\
\hline & $\delta_{1,10,2}\left(\mathrm{BGB}^{2}\right)$ & 0.038 & $4.30(0.000)$ & 0.009 \\
\hline \multirow{10}{*}{$S_{2}$} & $\beta_{2,1}(\mathrm{MSCI})$ & 0.134 & $1.19(0.237)$ & 0.112 \\
\hline & $\delta_{2,1,1}(\mathrm{SP})$ & 0.181 & $1.60(0.114)$ & 0.113 \\
\hline & $\delta_{2,2,1}\left(\operatorname{Gold}^{2}\right)$ & 0.099 & $2.26(0.028)$ & 0.044 \\
\hline & $\delta_{2,3,1}(\mathrm{TS})$ & 1.348 & $8.03(0.000)$ & 0.168 \\
\hline & $\delta_{2,3,2}\left(\mathrm{TS}^{2}\right)$ & -0.062 & $-12.32(0.000)$ & 0.005 \\
\hline & $\delta_{2,4,1}(\mathrm{CS})$ & 1.460 & $4.18(0.000)$ & 0.349 \\
\hline & $\delta_{2,5,1}(\mathrm{LS})$ & 0.188 & $3.48(0.001)$ & 0.054 \\
\hline & $\delta_{2,6,1}(\mathrm{VG})$ & -0.137 & $-3.10(0.003)$ & 0.044 \\
\hline & $\delta_{2,6,2}\left(\mathrm{VG}^{2}\right)$ & 0.019 & $3.07(0.003)$ & 0.006 \\
\hline & $\delta_{2,10,2}\left(\mathrm{BGB}^{2}\right)$ & 0.016 & $2.51(0.015)$ & 0.006 \\
\hline
\end{tabular}

Table 26: Fund Weighted: Parameter Estimates for the Quadratic Regime Switching Model with Financial Factors in Detail 


\begin{tabular}{|c|c|c|c|c|}
\hline \multicolumn{2}{|r|}{ Strategy } & \multicolumn{3}{|c|}{ 3-Funds of Funds } \\
\hline State & Variable & EsTIMATE & T-STAT (P-VALUE) & $\overline{\mathrm{SE}}$ \\
\hline \multirow{10}{*}{$S_{1}$} & $\beta_{1,1}(\mathrm{MSCI})$ & 0.231 & $6.56(0.000)$ & 0.035 \\
\hline & $\delta_{1,1,2}\left(\mathrm{SP}^{2}\right)$ & 0.092 & $2.58(0.011)$ & 0.036 \\
\hline & $\delta_{1,2,1}($ Gold $)$ & 0.066 & $2.56(0.011)$ & 0.026 \\
\hline & $\delta_{1,2,2}\left(\mathrm{Gold}^{2}\right)$ & 1.225 & $7.91(0.000)$ & 0.155 \\
\hline & $\delta_{1,3,1}(\mathrm{TS})$ & 0.327 & $1.41(0.160)$ & 0.232 \\
\hline & $\delta_{1,3,2}\left(\mathrm{TS}^{2}\right)$ & -1.267 & $-8.20(0.000)$ & 0.154 \\
\hline & $\delta_{1,5,1}(\mathrm{LS})$ & 0.077 & $1.89(0.060)$ & 0.041 \\
\hline & $\delta_{1,7,2}\left(\right.$ dVIX $\left.^{2}\right)$ & 0.156 & $1.87(0.063)$ & 0.083 \\
\hline & $\delta_{1,8,2}\left(\mathrm{MOM}^{2}\right)$ & 0.758 & $2.18(0.031)$ & 0.347 \\
\hline & $\delta_{1,10,2}\left(\mathrm{BGB}^{2}\right)$ & 0.046 & $4.46(0.000)$ & 0.010 \\
\hline \multirow{11}{*}{$S_{2}$} & $\beta_{2,1}(\mathrm{MSCI})$ & 0.099 & $2.36(0.021)$ & 0.042 \\
\hline & $\beta_{2,2}\left(\mathrm{MSCI}^{2}\right)$ & -0.016 & $-1.27(0.208)$ & 0.013 \\
\hline & $\delta_{2,2,1}($ Gold $)$ & 0.086 & $2.21(0.030)$ & 0.039 \\
\hline & $\delta_{2,3,1}(\mathrm{TS})$ & 1.407 & $9.52(0.000)$ & 0.148 \\
\hline & $\delta_{2,3,2}\left(\mathrm{TS}^{2}\right)$ & -0.060 & $-14.15(0.000)$ & 0.004 \\
\hline & $\delta_{2,4,1}(\mathrm{CS})$ & 1.315 & $3.85(0.000)$ & 0.341 \\
\hline & $\delta_{2,5,1}(\mathrm{LS})$ & 0.069 & $1.30(0.198)$ & 0.053 \\
\hline & $\delta_{2,5,2}\left(\mathrm{LS}^{2}\right)$ & -0.005 & $-1.08(0.284)$ & 0.005 \\
\hline & $\delta_{2,6,1}(\mathrm{VG})$ & -0.133 & $-3.27(0.002)$ & 0.041 \\
\hline & $\delta_{2,6,2}\left(\mathrm{VG}^{2}\right)$ & 0.011 & $2.05(0.044)$ & 0.005 \\
\hline & $\delta_{2,10,2}\left(\mathrm{BGB}^{2}\right)$ & 0.017 & $3.08(0.003)$ & 0.006 \\
\hline
\end{tabular}

Table 27: Funds of Funds: Parameter Estimates for the Quadratic Regime Switching Model with Financial Factors in Detail 


\begin{tabular}{|c|c|c|c|c|}
\hline \multicolumn{2}{|r|}{ Strategy } & \multicolumn{3}{|c|}{ 4-Macro } \\
\hline State & Variable & EsTIMATE & T-STAT (P-VALUE) & $\overline{\mathrm{SE}}$ \\
\hline \multirow{13}{*}{$S_{1}$} & $\beta_{1,1}(\mathrm{MSCI})$ & 0.222 & $2.51(0.013)$ & 0.088 \\
\hline & $\delta_{1,1,1}(\mathrm{SP})$ & 0.112 & $1.28(0.204)$ & 0.087 \\
\hline & $\delta_{1,1,2}\left(\mathrm{SP}^{2}\right)$ & 0.123 & $2.32(0.022)$ & 0.053 \\
\hline & $\delta_{1,2,1}($ Gold $)$ & 0.151 & $4.03(0.000)$ & 0.037 \\
\hline & $\delta_{1,2,2}\left(\mathrm{Gold}^{2}\right)$ & 0.720 & $3.18(0.002)$ & 0.226 \\
\hline & $\delta_{1,3,1}(\mathrm{TS})$ & 0.500 & $1.43(0.156)$ & 0.350 \\
\hline & $\delta_{1,3,2}\left(\mathrm{TS}^{2}\right)$ & -0.729 & $-3.27(0.001)$ & 0.223 \\
\hline & $\delta_{1,4,1}(\mathrm{CS})$ & -8.780 & $-1.47(0.144)$ & 5.978 \\
\hline & $\delta_{1,4,2}\left(\mathrm{CS}^{2}\right)$ & 0.023 & $1.78(0.078)$ & 0.013 \\
\hline & $\delta_{1,5,1}(\mathrm{LS})$ & 0.077 & $1.30(0.194)$ & 0.059 \\
\hline & $\delta_{1,7,2}\left(\mathrm{dVIX}^{2}\right)$ & 0.176 & $1.40(0.163)$ & 0.125 \\
\hline & $\delta_{1,8,2}\left(\mathrm{MOM}^{2}\right)$ & 5.363 & $1.60(0.113)$ & 3.361 \\
\hline & $\delta_{1,10,2}\left(\mathrm{BGB}^{2}\right)$ & 0.038 & $2.61(0.010)$ & 0.015 \\
\hline \multirow{12}{*}{$S_{2}$} & $\beta_{2,1}(\mathrm{MSCI})$ & 0.304 & $2.20(0.032)$ & 0.138 \\
\hline & $\delta_{2,1,1}(\mathrm{SP})$ & -0.207 & $-1.50(0.139)$ & 0.138 \\
\hline & $\delta_{2,2,1}($ Gold $)$ & 0.116 & $2.02(0.047)$ & 0.057 \\
\hline & $\delta_{2,2,2}\left(\mathrm{Gold}^{2}\right)$ & -0.381 & $-2.31(0.024)$ & 0.165 \\
\hline & $\delta_{2,3,1}(\mathrm{TS})$ & 0.833 & $2.16(0.035)$ & 0.386 \\
\hline & $\delta_{2,3,2}\left(\mathrm{TS}^{2}\right)$ & 0.326 & $2.01(0.048)$ & 0.162 \\
\hline & $\delta_{2,4,2}\left(\mathrm{CS}^{2}\right)$ & 0.008 & $1.39(0.171)$ & 0.006 \\
\hline & $\delta_{2,5,1}(\mathrm{LS})$ & 0.172 & $2.52(0.014)$ & 0.068 \\
\hline & $\delta_{2,6,1}(\mathrm{VG})$ & -0.095 & $-1.65(0.104)$ & 0.057 \\
\hline & $\delta_{2,6,2}\left(\mathrm{VG}^{2}\right)$ & 0.033 & $4.37(0.000)$ & 0.007 \\
\hline & $\delta_{2,7,2}\left(\right.$ dVIX $\left.^{2}\right)$ & 0.252 & $1.47(0.146)$ & 0.171 \\
\hline & $\delta_{2,9,2}\left(\mathrm{BGC}^{2}\right)$ & -0.008 & $-1.03(0.308)$ & 0.008 \\
\hline
\end{tabular}

Table 28: Macro: Parameter Estimates for the Quadratic Regime Switching Model with Financial Factors in Detail

\begin{tabular}{|c|c|c|c|c|}
\hline Strategy & 1-Emerging Markets & 2-Fund Weighted & 3-Funds of Funds & 4-Macro \\
\hline \hline State & & & & \\
\hline$S_{1}$ & $0.5641(0.000)$ & $0.882(0.000)$ & $0.863(0.000)$ & $0.7315(0.000)$ \\
\hline$S_{2}$ & $0.8184(0.000)$ & $0.8849(0.000)$ & $0.8868(0.000)$ & $0.7588(0.000)$ \\
\hline
\end{tabular}

Table 29: Adjusted- $R^{2}$ Values ( $p$-values) for the Multivariate Quadratic Regime Switching Model with Financial Factors 


\section{Quadratic with both Economic and Financial Factors}

\begin{tabular}{|c|c|c|c|c|}
\hline \multicolumn{2}{|r|}{ Strategy } & \multicolumn{3}{|c|}{ 1-Emerging Markets } \\
\hline State & Variable & EsTIMATE & T-STAT (P-VALUE) & $\mathrm{SE}$ \\
\hline \multirow{15}{*}{$S_{1}$} & $\beta_{1,1}(\mathrm{MSCI})$ & 0.342 & $2.73(0.007)$ & 0.125 \\
\hline & $\beta_{1,2}\left(\mathrm{MSCI}^{2}\right)$ & 0.018 & $1.15(0.253)$ & 0.016 \\
\hline & $\gamma_{1,1,1}(\mathrm{dGNP})$ & -0.796 & $-1.54(0.125)$ & 0.516 \\
\hline & $\gamma_{1,5,2}\left(\mathbf{I}^{2}\right)$ & -1.192 & $-2.34(0.021)$ & 0.510 \\
\hline & $\gamma_{1,6,1}(\mathrm{i})$ & 1.125 & $2.14(0.034)$ & 0.526 \\
\hline & $\gamma_{1,6,2}\left(\mathrm{i}^{2}\right)$ & -0.343 & $-4.33(0.000)$ & 0.079 \\
\hline & $\delta_{1,1,1}(\mathrm{SP})$ & 0.331 & $2.43(0.016)$ & 0.136 \\
\hline & $\delta_{1,2,1}$ (Gold) & 0.061 & $1.18(0.241)$ & 0.053 \\
\hline & $\delta_{1,3,1}(\mathrm{TS})$ & 0.990 & $2.04(0.044)$ & 0.487 \\
\hline & $\delta_{1,3,2}\left(\mathrm{TS}^{2}\right)$ & -0.079 & $-2.16(0.032)$ & 0.037 \\
\hline & $\delta_{1,4,1}(\mathrm{CS})$ & 15.963 & $1.83(0.069)$ & 8.722 \\
\hline & $\delta_{1,5,1}(\mathrm{LS})$ & 0.190 & $2.32(0.021)$ & 0.082 \\
\hline & $\delta_{1,6,1}(\mathrm{VG})$ & 0.119 & $1.21(0.230)$ & 0.098 \\
\hline & $\delta_{1,7,2}\left(\right.$ dVIX $\left.^{2}\right)$ & -0.366 & $-2.00(0.047)$ & 0.182 \\
\hline & $\delta_{1,8,2}\left(\mathrm{MOM}^{2}\right)$ & -6.604 & $-1.32(0.189)$ & 5.005 \\
\hline \multirow{15}{*}{$S_{2}$} & $\beta_{2,1}(\mathrm{MSCI})$ & 0.420 & $4.95(0.000)$ & 0.085 \\
\hline & $\beta_{2,2}\left(\mathrm{MSCI}^{2}\right)$ & -0.065 & $-2.76(0.008)$ & 0.0236 \\
\hline & $\gamma_{2,1,2}\left(\mathrm{dGNP}^{2}\right)$ & 0.936 & $3.32(0.002)$ & 0.282 \\
\hline & $\gamma_{2,2,1}(\mathrm{U})$ & 0.825 & $2.29(0.026)$ & 0.361 \\
\hline & $\gamma_{2,3,1}(\pi)$ & 3.792 & $2.84(0.006)$ & 1.334 \\
\hline & $\gamma_{2,3,2}\left(\pi^{2}\right)$ & -0.573 & $-2.79(0.007)$ & 0.206 \\
\hline & $\gamma_{2,4,1}(\mathrm{C})$ & 3.438 & $2.11(0.039)$ & 1.629 \\
\hline & $\gamma_{2,5,1}(\mathrm{I})$ & -1.534 & $-1.33(0.189)$ & 1.156 \\
\hline & $\gamma_{2,5,2}\left(\mathrm{I}^{2}\right)$ & 2.468 & $3.30(0.002)$ & 0.749 \\
\hline & $\gamma_{2,6,1}(\mathrm{i})$ & -0.071 & $-3.29(0.002)$ & 0.021 \\
\hline & $\delta_{2,2,1}($ Gold $)$ & 0.155 & $2.09(0.041)$ & 0.074 \\
\hline & $\delta_{2,2,2}\left(\mathrm{Gold}^{2}\right)$ & -0.13 & $-4.01(0.000)$ & 0.033 \\
\hline & $\delta_{2,3,1}(\mathrm{TS})$ & 1.470 & $3.34(0.001)$ & 0.439 \\
\hline & $\delta_{2,5,2}\left(\mathrm{LS}^{2}\right)$ & -0.017 & $-1.91(0.060)$ & 0.009 \\
\hline & $\delta_{2,10,2}\left(\mathrm{BGB}^{2}\right)$ & 0.017 & $1.83(0.072)$ & 0.009 \\
\hline
\end{tabular}

Table 30: Emerging Markets: Parameter Estimates for the Quadratic Regime Switching Model with both Economic and Financial Factors in Detail 


\begin{tabular}{|c|c|c|c|c|}
\hline \multicolumn{2}{|r|}{ Strategy } & \multicolumn{3}{|c|}{ 2-Fund Weighted } \\
\hline State & Variable & ESTIMATE & T-STAT (P-VALUE) & $\overline{S E}$ \\
\hline \multirow{19}{*}{$S_{1}$} & $\beta_{1,1}(\mathrm{MSCI})$ & 0.087 & $2.07(0.040)$ & 0.042 \\
\hline & $\gamma_{1,1,1}(\mathrm{dGNP})$ & -0.261 & $-1.81(0.072)$ & 0.144 \\
\hline & $\gamma_{1,2,1}(\mathrm{U})$ & -0.084 & $-1.21(0.228)$ & 0.069 \\
\hline & $\gamma_{1,4,1}(\mathrm{C})$ & 0.621 & $1.42(0.157)$ & 0.437 \\
\hline & $\gamma_{1,5,1}(\mathrm{I})$ & -0.401 & $-2.12(0.035)$ & 0.189 \\
\hline & $\gamma_{1,5,2}\left(\mathrm{I}^{2}\right)$ & -0.378 & $-1.89(0.061)$ & 0.200 \\
\hline & $\gamma_{1,6,1}(\mathrm{i})$ & -0.471 & $-3.70(0.000)$ & 0.127 \\
\hline & $\gamma_{1,6,2}\left(\mathrm{i}^{2}\right)$ & -0.070 & $-3.15(0.002)$ & 0.022 \\
\hline & $\delta_{1,1,1}(\mathrm{SP})$ & 0.257 & $5.55(0.000)$ & 0.0462 \\
\hline & $\delta_{1,1,2}\left(\mathrm{SP}^{2}\right)$ & 0.068 & $2.90(0.004)$ & 0.023 \\
\hline & $\delta_{1,2,1}$ (Gold) & 0.047 & $2.52(0.013)$ & 0.0185 \\
\hline & $\delta_{1,3,1}(\mathrm{TS})$ & 0.195 & $1.19(0.235)$ & 0.164 \\
\hline & $\delta_{1,4,1}(\mathrm{CS})$ & 1.172 & $2.70(0.008)$ & 0.433 \\
\hline & $\delta_{1,4,2}\left(\mathrm{CS}^{2}\right)$ & 0.015 & $1.90(0.059)$ & 0.008 \\
\hline & $\delta_{1,5,1}(\mathrm{LS})$ & 0.236 & $8.96(0.000)$ & 0.0264 \\
\hline & $\delta_{1,5,2}\left(\mathrm{LS}^{2}\right)$ & -0.012 & $-1.50(0.137)$ & 0.008 \\
\hline & $\delta_{1,6,2}\left(\mathrm{VG}^{2}\right)$ & -0.003 & $-1.72(0.087)$ & 0.002 \\
\hline & $\delta_{1,7,2}\left(\right.$ dVIX $\left.^{2}\right)$ & -0.075 & $-1.34(0.182)$ & 0.056 \\
\hline & $\delta_{1,10,2}\left(\mathrm{BGB}^{2}\right)$ & 0.012 & $1.91(0.058)$ & 0.006 \\
\hline \multirow{22}{*}{$S_{2}$} & $\beta_{2,2}\left(\mathrm{MSCI}^{2}\right)$ & -0.0213 & $-1.84(0.071)$ & 0.012 \\
\hline & $\gamma_{2,1,2}\left(\mathrm{dGNP}^{2}\right)$ & 0.436 & $2.52(0.015)$ & 0.173 \\
\hline & $\gamma_{2,3,1}(\pi)$ & 1.347 & $2.48(0.016)$ & 0.542 \\
\hline & $\gamma_{2,3,2}\left(\pi^{2}\right)$ & -0.262 & $-3.00(0.004)$ & 0.087 \\
\hline & $\gamma_{2,4,2}\left(\mathrm{C}^{2}\right)$ & 1.405 & $1.24(0.222)$ & 1.136 \\
\hline & $\gamma_{2,5,1}(\mathrm{I})$ & -1.252 & $-2.53(0.014)$ & 0.494 \\
\hline & $\gamma_{2,5,2}\left(\mathrm{I}^{2}\right)$ & 0.618 & $1.63(0.110)$ & 0.380 \\
\hline & $\gamma_{2,6,1}(\mathrm{i})$ & -0.651 & $-5.29(0.000)$ & 0.123 \\
\hline & $\delta_{2,1,1}(\mathrm{SP})$ & 0.233 & $5.58(0.000)$ & 0.0417 \\
\hline & $\delta_{2,2,1}($ Gold $)$ & 0.086 & $2.85(0.006)$ & 0.0301 \\
\hline & $\delta_{2,2,2}\left(\mathrm{Gold}^{2}\right)$ & 0.227 & $1.50(0.140)$ & 0.152 \\
\hline & $\delta_{2,3,1}(\mathrm{TS})$ & 0.771 & $2.80(0.007)$ & 0.275 \\
\hline & $\delta_{2,3,2}\left(\mathrm{TS}^{2}\right)$ & -0.276 & $-1.79(0.079)$ & 0.154 \\
\hline & $\delta_{2,4,1}(\mathrm{CS})$ & 4.543 & $2.18(0.034)$ & 2.083 \\
\hline & $\delta_{2,4,2}\left(\mathrm{CS}^{2}\right)$ & 0.008 & $1.13(0.263)$ & 0.007 \\
\hline & $\delta_{2,5,1}(\mathrm{LS})$ & 0.129 & $2.96(0.005)$ & 0.043 \\
\hline & $\delta_{2,5,2}\left(\mathrm{LS}^{2}\right)$ & -0.012 & $-1.44(0.156)$ & 0.008 \\
\hline & $\delta_{2,6,1}(\mathrm{VG})$ & -0.103 & $-2.80(0.007)$ & 0.037 \\
\hline & $\delta_{2,6,2}\left(\mathrm{VG}^{2}\right)$ & 0.010 & $2.28(0.027)$ & 0.005 \\
\hline & $\delta_{2,7,2}\left(\mathrm{dVIX}^{2}\right)$ & -0.256 & $-2.18(0.034)$ & 0.118 \\
\hline & $\delta_{2,8,2}\left(\mathrm{MOM}^{2}\right)$ & -1.201 & $-2.19(0.0327)$ & 0.547 \\
\hline & $\delta_{2,10,2}\left(\mathrm{BGB}^{2}\right)$ & 0.013 & $3.10(0.003)$ & 0.004 \\
\hline
\end{tabular}

Table 31: Fund Weighted: Parameter Estimates for the Quadratic Regime Switching Model with both Economic and Financial Factors in Detail 


\begin{tabular}{|c|c|c|c|c|}
\hline \multicolumn{2}{|r|}{ Strategy } & \multicolumn{3}{|c|}{ 3-Funds of Funds } \\
\hline State & Variable & ESTIMATE & T-STAT (P-VALUE) & $\mathrm{SE}$ \\
\hline \multirow{19}{*}{$S_{1}$} & $\beta_{1,1}(\mathrm{MSCI})$ & 0.074 & $1.50(0.137)$ & 0.049 \\
\hline & $\gamma_{1,1,2}\left(\mathrm{dGNP}^{2}\right)$ & -0.148 & $-1.18(0.240)$ & 0.126 \\
\hline & $\gamma_{1,2,1}(\mathrm{U})$ & -0.915 & $-1.74(0.085)$ & 0.527 \\
\hline & $\gamma_{1,2,2}\left(\mathrm{U}^{2}\right)$ & 0.058 & $1.42(0.157)$ & 0.041 \\
\hline & $\gamma_{1,5,1}(\mathrm{I})$ & -0.305 & $-1.19(0.236)$ & 0.257 \\
\hline & $\gamma_{1,5,2}\left(\mathrm{I}^{2}\right)$ & -0.312 & $-1.21(0.228)$ & 0.258 \\
\hline & $\gamma_{1,6,1}(\mathrm{i})$ & -0.470 & $-1.97(0.051)$ & 0.239 \\
\hline & $\gamma_{1,6,2}\left(\mathrm{i}^{2}\right)$ & -0.072 & $-2.25(0.026)$ & 0.032 \\
\hline & $\delta_{1,1,1}(\mathrm{SP})$ & 0.144 & $2.62(0.010)$ & 0.055 \\
\hline & $\delta_{1,1,2}\left(\mathrm{SP}^{2}\right)$ & 0.089 & $2.94(0.004)$ & 0.031 \\
\hline & $\delta_{1,2,1}($ Gold $)$ & 0.058 & $2.49(0.014)$ & 0.024 \\
\hline & $\delta_{1,2,2}\left(\right.$ Gold $\left.^{2}\right)$ & 0.030 & $1.99(0.048)$ & 0.015 \\
\hline & $\delta_{1,5,1}(\mathrm{LS})$ & 0.131 & $3.87(0.0002)$ & 0.034 \\
\hline & $\delta_{1,5,2}\left(\mathrm{LS}^{2}\right)$ & 0.009 & $1.27(0.205)$ & 0.007 \\
\hline & $\delta_{1,6,1}(\mathrm{VG})$ & 0.085 & $2.05(0.042)$ & 0.041 \\
\hline & $\delta_{1,6,2}\left(\mathrm{VG}^{2}\right)$ & -0.003 & $-1.11(0.268)$ & 0.002 \\
\hline & $\delta_{1,8,2}\left(\mathrm{MOM}^{2}\right)$ & 0.465 & $1.45(0.148)$ & 0.320 \\
\hline & $\delta_{1,9,2}\left(\mathrm{BGC}^{2}\right)$ & -0.016 & $-1.93(0.056)$ & 0.008 \\
\hline & $\delta_{1,10,2}\left(\mathrm{BGB}^{2}\right)$ & 0.015 & $1.80(0.074)$ & 0.008 \\
\hline \multirow{19}{*}{$S_{2}$} & $\beta_{2,1}$ (MSCI) & 0.074 & $1.87(0.066)$ & 0.040 \\
\hline & $\beta_{2,2}\left(\mathrm{MSCI}^{2}\right)$ & -0.026 & $-2.41(0.019)$ & 0.011 \\
\hline & $\gamma_{2,1,2}\left(\mathrm{dGNP}^{2}\right)$ & 0.296 & $1.77(0.083)$ & 0.168 \\
\hline & $\gamma_{2,2,1}(\mathrm{U})$ & -4.098 & $-2.25(0.028)$ & 1.818 \\
\hline & $\gamma_{2,2,2}\left(\mathrm{U}^{2}\right)$ & 0.262 & $2.09(0.041)$ & 0.126 \\
\hline & $\gamma_{2,3,1}(\pi)$ & 0.646 & $2.93(0.005)$ & 0.220 \\
\hline & $\gamma_{2,5,1}(\mathrm{I})$ & -0.683 & $-1.80(0.077)$ & 0.379 \\
\hline & $\gamma_{2,5,2}\left(\mathrm{I}^{2}\right)$ & 0.638 & $1.81(0.076)$ & 0.352 \\
\hline & $\gamma_{2,6,1}(\mathrm{i})$ & -0.475 & $-3.179(0.002)$ & 0.149 \\
\hline & $\delta_{2,1,2}\left(\mathrm{SP}^{2}\right)$ & 0.044 & $2.06(0.044)$ & 0.021 \\
\hline & $\delta_{2,2,1}($ Gold $)$ & 0.070 & $2.05(0.045)$ & 0.034 \\
\hline & $\delta_{2,2,2}\left(\right.$ Gold $\left.^{2}\right)$ & 0.500 & $1.80(0.078)$ & 0.278 \\
\hline & $\delta_{2,3,1}(\mathrm{TS})$ & 1.282 & $3.78(0.000)$ & 0.339 \\
\hline & $\delta_{2,3,2}\left(\mathrm{TS}^{2}\right)$ & -0.429 & $-1.59(0.117)$ & 0.269 \\
\hline & $\delta_{2,4,1}(\mathrm{CS})$ & 2.459 & $2.15(0.036)$ & 1.142 \\
\hline & $\delta_{2,4,2}\left(\mathrm{CS}^{2}\right)$ & 0.008 & $0.98(0.331)$ & 0.008 \\
\hline & $\delta_{2,5,2}\left(\mathrm{LS}^{2}\right)$ & -0.011 & $-1.27(0.209)$ & 0.009 \\
\hline & $\delta_{2,6,1}(\mathrm{VG})$ & -0.118 & $-3.03(0.004)$ & 0.039 \\
\hline & $\delta_{2,10,2}\left(\mathrm{BGB}^{2}\right)$ & 0.012 & $2.65(0.011)$ & 0.005 \\
\hline
\end{tabular}

Table 32: Funds of Funds: Parameter Estimates for the Quadratic Regime Switching Model with both Economic and Financial Factors in Detail 


\begin{tabular}{|c|c|c|c|c|}
\hline \multicolumn{2}{|r|}{ Strategy } & \multicolumn{3}{|c|}{ 4-Macro } \\
\hline State & Variable & ESTIMATE & T-STAT (P-VALUE) & $\mathrm{SE}$ \\
\hline \multirow{15}{*}{$S_{1}$} & $\beta_{1,1}(\mathrm{MSCI})$ & 0.107 & $1.24(0.217)$ & 0.086 \\
\hline & $\gamma_{1,1,2}\left(\mathrm{dGNP}^{2}\right)$ & -0.502 & $-2.45(0.015)$ & 0.204 \\
\hline & $\gamma_{1,5,2}\left(\mathrm{I}^{2}\right)$ & -0.696 & $-2.09(0.038)$ & 0.333 \\
\hline & $\gamma_{1,6,2}\left(\mathrm{i}^{2}\right)$ & -0.103 & $-6.13(0.000)$ & 0.017 \\
\hline & $\delta_{1,1,1}(\mathrm{SP})$ & 0.236 & $2.77(0.006)$ & 0.085 \\
\hline & $\delta_{1,1,2}\left(\mathrm{SP}^{2}\right)$ & 0.131 & $2.52(0.013)$ & 0.052 \\
\hline & $\delta_{1,2,1}$ (Gold) & 0.128 & $3.63(0.000)$ & 0.035 \\
\hline & $\delta_{1,3,1}(\mathrm{TS})$ & 0.331 & $2.04(0.043)$ & 0.162 \\
\hline & $\delta_{1,4,1}(\mathrm{CS})$ & -3.956 & $-2.52(0.013)$ & 1.572 \\
\hline & $\delta_{1,4,2}\left(\mathrm{CS}^{2}\right)$ & 0.028 & $2.26(0.025)$ & 0.012 \\
\hline & $\delta_{1,5,1}(\mathrm{LS})$ & 0.0865 & $1.53(0.128)$ & 0.057 \\
\hline & $\delta_{1,6,1}(\mathrm{VG})$ & 0.113 & $1.63(0.105)$ & 0.069 \\
\hline & $\delta_{1,8,2}\left(\mathrm{MOM}^{2}\right)$ & 2.899 & $2.57(0.011)$ & 1.128 \\
\hline & $\delta_{1,9,2}\left(\mathrm{BGC}^{2}\right)$ & -0.014 & $-1.05(0.297)$ & 0.014 \\
\hline & $\delta_{1,10,2}\left(\mathrm{BGB}^{2}\right)$ & 0.024 & $1.814(0.071)$ & 0.013 \\
\hline \multirow{16}{*}{$S_{2}$} & $\beta_{2,1}(\mathrm{MSCI})$ & 0.095 & $2.26(0.027)$ & 0.042 \\
\hline & $\gamma_{2,2,1}(\mathrm{U})$ & -0.343 & $-1.55(0.126)$ & 0.222 \\
\hline & $\gamma_{2,3,1}(\pi)$ & 0.580 & $1.41(0.164$ & 0.411 \\
\hline & $\gamma_{2,3,2}\left(\pi^{2}\right)$ & -0.204 & $-2.56(0.013)$ & 0.079 \\
\hline & $\gamma_{2,6,1}(\mathrm{i})$ & -1.499 & $-3.31(0.002)$ & 0.453 \\
\hline & $\gamma_{2,6,2}\left(\mathrm{i}^{2}\right)$ & 0.085 & $1.60(0.114)$ & 0.053 \\
\hline & $\delta_{2,1,2}\left(\mathrm{SP}^{2}\right)$ & 0.039 & $1.40(0.167)$ & 0.028 \\
\hline & $\delta_{2,2,1}$ (Gold) & 0.104 & $2.44(0.018)$ & 0.043 \\
\hline & $\delta_{2,4,1}(\mathrm{CS})$ & 4.842 & $1.79(0.078)$ & 2.701 \\
\hline & $\delta_{2,4,2}\left(\mathrm{CS}^{2}\right)$ & 0.028 & $2.83(0.006)$ & 0.010 \\
\hline & $\delta_{2,5,1}(\mathrm{LS})$ & 0.151 & $2.73(0.008)$ & 0.055 \\
\hline & $\delta_{2,5,2}\left(\mathrm{LS}^{2}\right)$ & -0.028 & $-2.44(0.018)$ & 0.011 \\
\hline & $\delta_{2,6,1}(\mathrm{VG})$ & -0.085 & $-1.93(0.059)$ & 0.044 \\
\hline & $\delta_{2,6,2}\left(\mathrm{VG}^{2}\right)$ & 0.019 & $2.96(0.004)$ & 0.007 \\
\hline & $\delta_{2,7,2}\left(\mathrm{dVIX}^{2}\right)$ & -0.139 & $-1.10(0.277)$ & 0.126 \\
\hline & $\delta_{2,8,2}\left(\mathrm{MOM}^{2}\right)$ & -1.365 & $-1.84(0.071)$ & 0.743 \\
\hline
\end{tabular}

Table 33: Macro: Parameter Estimates for the Quadratic Regime Switching Model with both Economic and Financial Factors in Detail

\begin{tabular}{|c|c|c|c|c|}
\hline Strategy & 1-Emerging Markets & 2-Fund Weighted & 3-Funds of Funds & 4-Macro \\
\hline \hline State & & & & \\
\hline$S_{1}$ & $0.6375(0.000)$ & $0.9386(0.000)$ & $0.9163(0.000)$ & $0.7657(0.000)$ \\
\hline$S_{2}$ & $0.8625(0.000)$ & $0.9517(0.000)$ & $0.9285(0.000)$ & $0.863(0.000)$ \\
\hline
\end{tabular}

Table 34: Adjusted- $R^{2}$ Values ( $p$-values) for the Multivariate Quadratic Regime Switching Model with both Economic and Financial Factors 


\section{References}

Agarwal, V. and N. Naik, 2004, "Risks and Portfolio Decisions Involving Hedge Funds", Review of Financial Studies 17, 63-98.

Alexander, C., and A. Dimitriu, 2005, "Indexing, Cointegration and Equity Market Regimes", International Journal of Finance and Economics 10, 1-10.

Bekaert, G. and C. Harvey, 1995, “Time-Varying World Market Integration”, The Journal of Finance 50, 2, 403-444.

Bhar, R. and S. Hamori, 2004, "Hidden Markov Models: Applications to Financial Economics", (Chapter 1), Springer.

Billio, M., Getmansky M., and L. Pelizzon, 2010, Dynamic Risk Exposure in Hedge Funds, Yale ICF WP 07-14, forthcoming Computational Statistics and Data Analysis

Blazsek, S. and A. Downarowicz, 2006, "Regime Switching Models of Hedge Fund Returns", University of Navarra Working Paper.

Chan, N., Getmansky, M., Haas, S. and A. Lo., 2005, "Systemic Risk and Hedge Funds", NBER Book On Risks of Financial Institutions, Topic: Systemic Risk.

Gordon, S. and F. Vlavonou, 2012, "Integrating Quarterly Data into a Dynamic Factor Model of US Monthly GDP", Laval University Working Paper

Forbes, K. and R. Rigobon, 2002, "No Contagion, Only Interdependence: Measuring Stock Market Co-Movements", The Journal of Finance 57, 5, 2223- 2261. 
French, M. W., 2005, "A Nonlinear Look at Trend MFP Growth and the Business Cycle: Result from a Hybrid Kalman/Markov Switching Model". FEDS Working Paper No. 2005-12.

Fung, W. and D. Hsieh, 1997a, "Empirical Characteristics of Dynamic Trading Strategies: The Case of Hedge Funds", Review of Financial Studies 10, 275-302.

Fung, W. and D. Hsieh, 2001, "The Risk in Hedge Fund Strategies: Theory and Evidence from Trend Followers", Review of Financial Studies 14, 313-341.

Giamouridis, D. and I. D. Vrontos, 2007, "Hedge Fund Portfolio Construction: A Comparison of Static and Dynamic Approaches", Journal of Banking and Finance, $31,1,199-217$

Goetzmann, W., Ingersoll, J., Spiegel, M. and I. Welch, 2006, "Portfolio Performance Manipulation and Manipulation-Proof Performance Measures", Review of Financial Studies 20, 5, 1503-1546.

Hamilton, J., 1989, “A New Approach to the Economic Analysis of Nonstationary Time Series and the Business Cycle", Econometrica 57, 357-38.

Olivares, P., Reus, A., Seco, L., and R. Zagst, 2011, "Risk Management and Portfolio selection using $\alpha$ - stable regime switching models", HVB - Institute for Mathematical Finance Working Paper

Racicot, F. É., and R. Théoret, 2009, "Modeling Hedge Fund Returns Using the Kalman Filter: An Errors-in-Variables Perspective", University of Québec Working Paper.

Roncalli, T. and J. Teïletche, 2007, "An Alternative Approach to Alternative Beta", Journal of Financial Transformation 24, 43-52. 